Document downloaded from:

http://hdl.handle.net/10251/125114

This paper must be cited as:

Esteso, A.; Alemany Díaz, MDM.; Ortiz Bas, A. (2018). Conceptual framework for designing agri-food supply chains under uncertainty by mathematical programming models.

International Journal of Production Research. 56(13):4418-4446.

https://doi.org/10.1080/00207543.2018.1447706

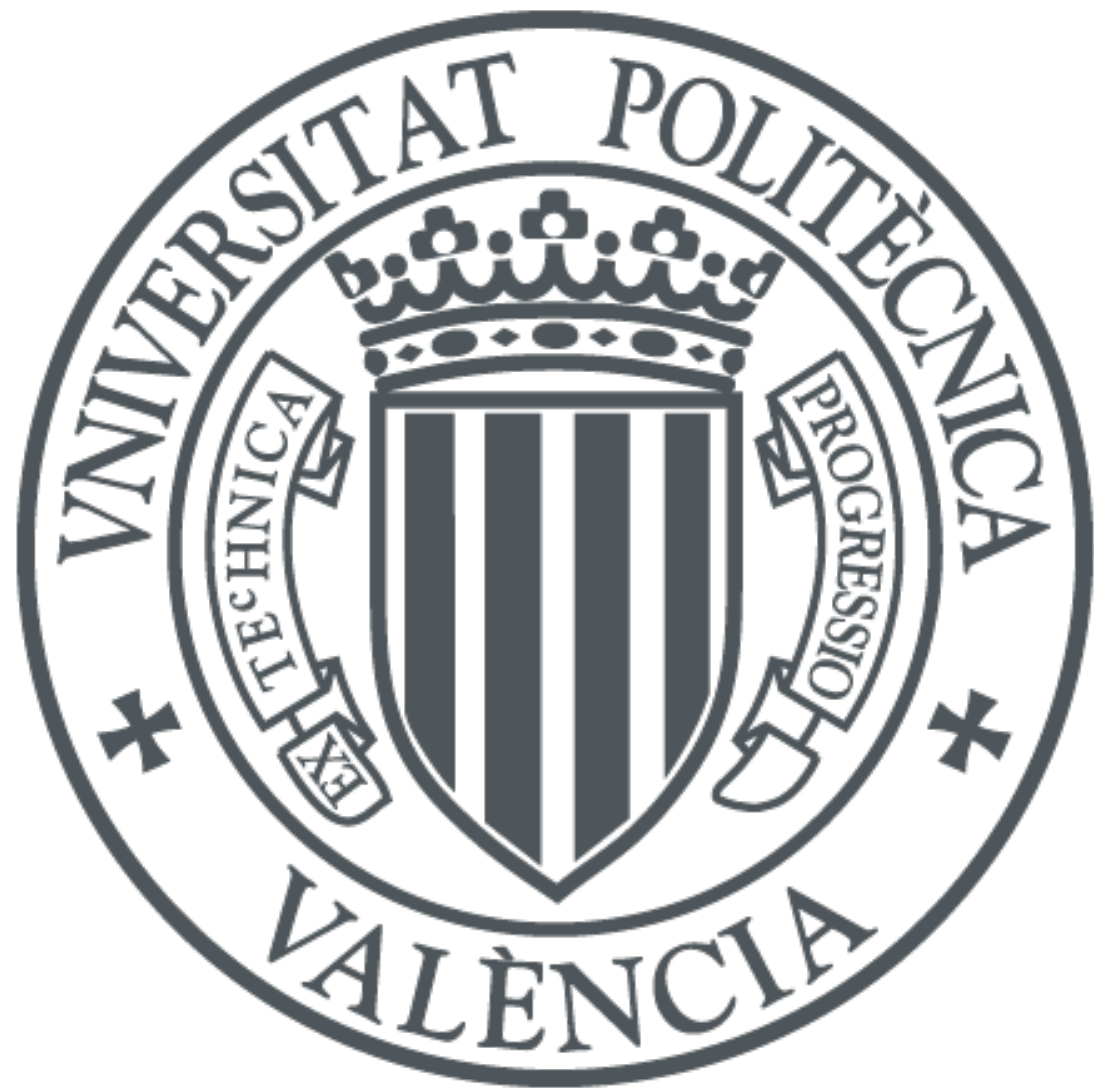

The final publication is available at

http://doi.org/10.1080/00207543.2018.1447706

Copyright Taylor \& Francis

Additional Information

This is an Author's Accepted Manuscript of an article published in [include the complete citation information for the final version of the article as published in the International Journal of Production Research (2018) (C) Taylor \& Francis, available online at:

http://doi.org/10.1080/00207543.2018.1447706 


\section{Conceptual Framework for Designing Agri-Food Supply Chains under Uncertainty by Mathematical Programming Models}

Ana Esteso $^{\mathrm{a}^{*}}$, M.M.E. Alemany ${ }^{\mathrm{a}}$, Ángel Ortiz ${ }^{\mathrm{a}}$

${ }^{\mathrm{a}}$ Research Centre on Production Management and Engineering (CIGIP), Universitat

Politècnica de València, Camino de Vera S/N, 46002, Valencia, Spain

*Corresponding author: Ana Esteso: Tel. +34647885671 Email: aneslva@ doctor.upv.es

MME Alemany, Tel. +34963877007 ext. 76868 Email: mareva@cigip.upv.es

Ángel Ortiz: Tel. +34963879680 Email: aortiz@ cigip.upv.es 


\title{
Conceptual Framework for Designing Agri-Food Supply Chains under Uncertainty by Mathematical Programming Models
}

\begin{abstract}
Agri-food sector performance strongly impacts global economy, which means that developing optimisation models to support the decision-making process in agrifood supply chains (AFSC) is necessary. These models should contemplate AFSC's inherent characteristics and sources of uncertainty to provide applicable and accurate solutions. To the best of our knowledge, there are no conceptual frameworks available to design AFSC through mathematical programming modelling while considering their inherent characteristics and sources of uncertainty, nor any there literature reviews that address such characteristics and uncertainty sources in existing AFSC design models. This paper aims to fill these gaps in the literature by proposing such a conceptual framework and state of the art. The framework can be used as a guide tool for both developing and analysing models based on mathematical programming to design AFSC. The implementation of the framework into the state of the art validates its. Finally, some literature gaps and future research lines were identified.
\end{abstract}

Keywords: agri-food supply chain; design; uncertainty; conceptual framework; literature review

\section{Introduction}

Agri-Food Supply Chains (AFCS) are responsible for bringing agricultural products from the farm to the fork (Esteso, Alemany, and Ortiz, in press). Since these supply chains (SC) comprise the largest manufacturing sector in Europe, and contribute to the economy with 4.25 million employees and a turnover over $€ 1$ trillion, it is critical to develop effective and efficient models and methods to support AFSC decision-making processes and to optimise AFSC performance (Amorim et al. 2016, FoodDrink Europe 2016).

Such performance is strongly influenced by factors such as uncertainty sources (e.g. weather, diseases, pests) and product characteristics (e.g. perishability), which differentiate AFSC from other industrial SC. Therefore, generic decision-making models 
and methods for designing and operating SC cannot be easily extrapolated to the agrifood sector since they do not represent real AFSC performance.

A first step, and one of the most critical ones for optimising AFSC performance, is to adequately design them as tactical and operational decisions, as well as their impact on overall SC performance, will depend on their configuration (Baghalian, Rezapour, and Farahani 2013). Tsolakis et al. (2014) point out that despite the significance of SC configuration decisions and a number of papers that address them in the general SC management context, the relevant agri-food literature on this topic is limited. This is probably due to the difficulties imposed by the structure and complexity of an entire agrifood chain's relationships, and to incoming uncertainties that characterise this particular network type.

In their review of operational research models applied to fresh fruit SC, Soto-Silva et al. (2016) state that there is a gap of models to design and manage such SC. These authors note that practically all models consider a constant price over time without taking into account fruit seasonality or loss in the product's value due to product deterioration. They point out the need for tools that incorporate fresh fruit SC's characteristics, such as shelf life, quality deterioration, waste, and prices that depend on time and product freshness. They also indicate that given the uncertainty and risk that surround the fresh fruit sector, it is necessary to develop models that include these characteristics. Along these lines, Nakandala, Lau and Zhao (2017) proposed a hybrid model for assessing risk in fresh food supply chains.

Since inherent sources of uncertainty in AFSC have a negative impact on their performance and sustainability, several authors (Ahumada and Villalobos 2009; Akkerman, Farahani, and Grunow 2010; Borodin et al. 2016; de Keizer et al. 2015; Lucas and Chhajed 2004; Tsolakis et al. 2014) state the need to develop AFSC design models 
that contemplate the effect of existing uncertainty sources and product perishability throughout the chain.

In order to formulate such models, it is necessary to: 1) define AFSC's characteristics, uncertainty sources, decisions and mathematical programming approaches that can be addressed and employed when designing AFSC; 2) establish the state of the art of such items to know current research and to detect existing gaps in the literature.

For the purpose of determining if previous works have met these needs, a review of existing conceptual frameworks $(\mathrm{CF})$ covering the AFSC design problem and literature reviews (LR) of AFSC design models was done. It is worth mentioning that this review was restricted to $\mathrm{CF}$ that deal with the strategic decision "Configuration of SC category" within the Hierarchical Decision Framework for AFSC management proposed by Tsolakis et al. (2014). Consequently, other CF types that address strategic decisions of other categories are beyond scope of this research. This is the case of the CF of Hobbs and Young (2000) and the CF of Zhang and Aramyan (2009), which deal with the strategic decision "Fostering SC Partnering Relationship category" (see Tsolakis et al. 2014). This is why they are not analysed herein.

The results of this review (Table 1) showed that existing CF focus mainly on providing managerial insights for the AFSC design process. It was also determined that: 1) existing $\mathrm{CF}$ are not based on or developed to think in mathematical programming models; 2) do not consider AFSC's inherent characteristics; nor 3) sources of uncertainty simultaneously. The studied LR do not define the main AFSC's inherent characteristics and uncertainty sources, nor which have been addressed by existing models, or how they have been modelled.

[Table 1 near here] 
This paper aims to fill these literature gaps by following a research methodology that comprises two phases. The first phase is to propose a CF to develop and/or analyse AFSC design mathematical programming models, while considering AFSC's inherent characteristics and uncertainty sources. The second phase consists in using the proposed CF for reviewing existing AFSC design models to determine if such characteristics have been addressed and to identify possible literature gaps. This second phase validates the proposed framework.

The results of this paper show that existing AFSC design models have not addressed product characteristics simultaneously, such as perishability, food quality, food safety or product heterogeneity. Uncertainty is considered in a few papers, but they have not modelled the AFSC's own uncertainty sources (e.g. weather, food quality, food safety, perishability), rather the generic ones found in SC from different sectors (e.g. demand, lead time).

The remainder of the paper is structured as follows. Section 2 proposes a CF to design AFSC, while considering their inherent characteristics and uncertainty sources through mathematical programming modelling. Since the different items to be contemplated while designing AFSC are defined within this framework, Section 3 uses them to establish the current state of the art of AFSC design models and to detect any possible gaps in them. Finally, Section 4 sets out the conclusions and future research lines.

\section{Conceptual Framework for AFSC Design Models}

This section describes the proposed CF to design AFSC whose purpose is to be used as a guide tool to both develop accurate mathematical programming models to design specific AFSC and to analyse existing ones.

The proposed CF aim to identify all the inherent characteristics to the AFSC design problem. For this reason, some of their characteristics are common to other generic 
SC design models as they deal with the same problem (SC design), whereas other characteristics are specific for the agri-food sector. As justified in the Introduction, these AFSC specific features strongly impact AFSC performance and efficiency, which render their consideration necessary. Therefore, employing already existing generic models to design AFSC could lead to poorer SC performance than the performance expected when using AFSC design models considering inherent characteristics to the agri-food sector. For example, if the product freshness requirement is not considered when designing AFSC, a SC with very long transport times can be designed, during which products will lose their freshness and then, become unmarketable.

The CF is based on that proposed by Grillo, Alemany and Ortiz (2016) to characterise quantitative models by contemplating Lack of Homogeneity in the Product (LHP) characteristics and/or uncertainty during the Order Promising Process (OPP), where LHP is identified to be present in AFSC. In this paper, this framework was extended and adjusted to the AFSC design problem in the following way.

The "Environment" dimension was replaced with the "AFSC characteristics" dimension where the main agri-food issues to be considered when designing AFSC were defined (Section 3.1). The OPP-related dimensions were replaced with the "Decision characteristics" where design decisions were focused on (Section 3.2). The "Modelling approach" dimension was extended by adding the constraints to be contemplated when designing AFSC (Section 3.3.). Finally, the way of modelling sources of uncertainty was also included in the "Uncertainty modelling" dimension (Section 3.4).

Therefore, the proposed CF was divided into four blocks (Figure 1) that represent the pillars needed to develop an AFSC design model. Each block was divided into a series of specific categories of the problem under study that differentiated this CF from that proposed by Grillo, Alemany and Ortiz (2016). 
[Figure 1 near here]

\subsection{AFSC Characteristics}

This dimension is composed of four categories: 1) Subsector, where the agri-food sector is subdivided into subsectors; 2) SC stages showing the existing AFSC stages; 3) number of products where the different products produced by AFSC were identified; 4) product characteristics, where the characteristics inherent of agri-food products were identified.

\subsubsection{Subsector}

Many products can be obtained from AFSC, such as rice, beef, carrots or apples. These SC products are different in terms of the needed productive processes, product characteristics and legislation, which makes their management and design very different.

For this reason, it is necessary to classify the agri-food sector into subsectors. This CF proposes distinguishing between: 1) crop-based AFSC and 2) animal-based AFSC as their products and productive processes vastly differ. In addition, it is interesting to subdivide the crop-based AFSC into: 1.a) highly perishable AFSC (vegetables and fruits), and 1.b) slightly perishable AFSC (cereals, tubs, nuts) (Ahumada and Villalobos, 2009).

\subsubsection{Supply Chain Stages}

According to Chopra and Meindl (2007), SC can be divided into five stages:

- Supplier

- Processor.

- Distributor.

- Retailer.

- Customer. 
In this sector, farmers are considered the suppliers of SC, although they have, in turn, their own suppliers (e.g. seed or fertilizer companies). They all perform add-value activities with products, such as packaging in fresh fruit SC, or slaughtering, cutting up and packaging in beef SC, and are considered processors. Distributors are responsible for storing and distributing products to retailers, who sell the finished product to end customers. Finally, customers represent the market's final demand.

\subsubsection{Number of Products}

AFSC can be designed to manage one product or more, which makes SC management more complicated when more products are simultaneously managed. However, given product seasonality in some agri-food subsectors (e.g. vegetables and fruits), it is interesting to design AFSC capable of simultaneously managing more than one product variety (e.g. different varieties of apples) or even different products (e.g. spinach, lettuce and cauliflower).

\subsubsection{Product Characteristics}

Agri-food products are characterised mainly by their perishability, represented by considering products' remaining shelf life until they become inedible for humans and/or by contemplating a product deterioration rate that depends on time and/or environmental factors (e.g. temperature or humidity). New technologies allow the monitoring of relevant attributes of products in real time. For instance, it is possible to use sensors to estimate the remaining shelf-life of agri-food products during their transport and management, what allows to determine prices dependent on the remaining shelf-life ( $\mathrm{Li}$ and Wang 2017).

Other characteristics of agri-food products are the food quality and food safety requirements imposed by end customers and/or governments. Food quality is measured 
by a product's physical attributes (e.g. taste, texture, colour) and customers' perceptions of them, while food safety can be measured as a binary variable to determine if a product is allowed for consumption or not to prevent illnesses caused by contaminated products (Akkerman, Farahani, and Grunow 2010).

Finally, agri-food products are also characterised by heterogeneity between units of the same product in physical attributes and perishability terms. For example, two apples harvested at the same time from one same tree, or two similarly fed chickens of similar age, can present different physical attributes (weight, colour, taste, texture, etc.) and distinct deterioration rates.

In some cases, product characteristics can be interrelated and considered equivalents, but this does not occur in all AFSC types. For example, some authors claim that product quality is linked directly to its freshness, whereas others state that product quality and freshness can be considered differentiated characteristics according to AFSC (Grillo et al. 2017). Therefore, depending on the specific case for which the AFSC design model is developed, researchers and practitioners can decide to either consider these characteristics separately or, on the contrary, integrate some of them in order to lessen the model's complexity.

\subsection{Decision Characteristics}

This dimension is composed of three categories: 1) Design decisions, where the possible decisions to be made when designing AFSC are identified; 2) Additional decisions, where planning and/or operational decisions made while designing AFSC are exposed; 3) Time horizon, where the horizon to be considered needs to be decided.

\subsubsection{Design Decisions}

Chopra and Meindl (2007) proposed four decisions to design SC (facility role, facility 
location, capacity allocation, market \& supply allocation). This approach has been extended in this CF by considering the following decisions:

- Facility role: defining the processes to be performed at each facility and/or the facility type to be opened at each location

- Facility location: deciding where to locate a facility

- Capacity allocation: defining the capacity to allocate each facility

- Maintain/Close facility: decision as to whether to close or keep open locations over the horizon

- Supply allocation: selecting which suppliers will provide each processor

- Facilities allocation: defining the connections among AFSC's nodes

- Market allocation: selecting which facilities will serve each retailer or end customer

It is necessary to differentiate between models developed to design SC and models developed to design a particular facility. SC design models will pursue objectives that benefit the whole SC such as in Allaoui et al. (2016). Meanwhile, a facility design model will only look for the benefit of the particular facility, such as in Meneghetti and Monti (2015).

\subsubsection{Additional Decisions}

Design decisions are not usually isolated, but are accompanied by other SC decisions. Melo, Nickel and Saldanha-da-Gama (2009) proposed a list of five planning decisions to be considered when designing $\mathrm{SC}$, which has been extended in this $\mathrm{CF}$ to represent the most important decisions in AFSC:

- Energy type: energy source to be used in each AFSC process 
- Inventory: product quantities to store per facility and time period

- Labouring: number of labourers needed at each facility

- Procurement: amount of raw materials or products to buy from suppliers

- Production: amount of product to be manufactured in each production plant

- Routing: definition of the routes to follow during product distribution

- Transported quantity: product quantity to be transported between locations

- Transport mode: transport mode to be used for each delivery

- Transport capacity: allocation of transport capacity

\subsubsection{Time Horizon}

An AFSC can be designed by considering a single time period or multiple time periods. Depending on the problem to be addressed (considered design decisions, additional decisions and AFSC characteristics), it might be more appropriate to consider one time period or more when designing AFSC. The correct selection of the time horizon to be considered when designing AFSC can lead to more accurate results for AFSC behaviour, but also to more complex models.

\subsection{Modelling Approach}

This dimension is made up of four categories: 1) Model type, where the employed modelling type is decided; 2) Model purpose, where the model's objectives are set; 3) Model constraints, where the model constraints are decided; 4) Model application, where the model application to real cases or cases studies is stated.

\subsubsection{Model Type}

The taxonomy proposed by Mula et al. (2010) for classifying model types is adopted in 
this category:

- Linear programming: it can be divided into Linear programming (LP) and Mixed integer/Integer linear programming (MILP)

- Non-linear programming: it can be divided into Non-linear programming (NLP) and Mixed integer/Integer non-linear programming (INLP)

- Multi-objective programming: it can be divided into Multi-objective linear programming (MOLP), Multi-objective integer linear programming (MOILP), Multi-objective non-linear programming (MONLP) and Multi-objective nonlinear integer programming (MONLIP)

- Fuzzy programming: composed of Fuzzy mathematical programming (FMP)

- Stochastic programming (SP)

- Heuristics, algorithms and metaheuristics (HEU)

- Hybrid models (HYB)

Another classification of optimisation approaches can be adopted when considering multiple models to solve specific problems. This is the case of the multi-level, multistage or multi-echelon modelling approaches. Multi-level models are applied to decentralised planning problems with multiple decision makers who sequentially make decisions based on his/her own model in a multi-level or hierarchical organisation. Bilevel programming is a specific case of the multi-level type, but with only two decision makers at two different hierarchical levels (Shih et al. 1996). Multi-stage models deal with a single decision maker who must make a sequence of decisions over time to react to changing conditions. Both these optimisation approaches are normally used as decomposition techniques that divide the complex problem into inter-connected simpler subproblems to diminish the complexity of the solution. Finally, and broadly speaking, 
the multi-echelon inventory theory is concerned with a variety of inventory problems that comprise two interrelated supply or production facilities or more (Clark 1972). The places where the inventory is kept in the SC are called "echelons". Usually the complexity of a SC is related to the number of echelons that it incorporates (Tsiakis, Shah \& Pantelides 2001).

\subsubsection{Model Purpose}

Models can pursue different objectives that can be related to various sustainability aspects. According to Farahani et al. (2014), a SC is sustainable when it considers economic, environmental and social aspects. However, it is called a "Green supply chain" if it considers environmental and economic aspects, or is known as a "Lean supply chain" when it considers only the economical aspect.

The agri-food sector has a huge impact on Europe's economy ( $€ 1$ trillion turnover), the environment (25.7\% of Europe's energy use) and society (4.25 million employees) (FoodDrink Europe 2016; Monforti-Ferrario et al. 2015). In order to attempt to optimise AFSC performance and generate a positive impact on a nation's sustainability, it is important to develop models that pursue objectives related to the three pillars of sustainability: 1) economical aspect (maximise profits or minimise costs), 2) environmental aspect (minimise $\mathrm{CO}_{2}$ emissions, water/energy use and waste); 3) social aspect (e.g. maximise employment creation, customer satisfaction, or minimise delivery times).

\subsubsection{Model Constraints}

When designing a SC, it is important to consider the constraints that limit the decisionmaker power of decisions. As the AFSC design problem is usually addressed while devising planning and/or operational decisions, the constraints related to these decisions 
should also be considered. Therefore, the constraints to be contemplated depend on the decisions to be made.

Some possible constraints to be considered are those related with: 1) supply (e.g. available quantity in suppliers); 2) capacity (e.g. capacity of facilities, transport capacity); 3) number of locations (e.g. minimum, maximum or the exact number of locations to be opened or operated simultaneously); 4) distance (e.g. minimum or maximum allowable distance between locations, maximum transport distance); 5) budget (e.g. budget available to open locations); 6) product flow (e.g. maximum quantity to be handled at a facility); 7) time (e.g. maximum transport time, deliveries time window, working time limitations); 8) service level (e.g. minimum service level); 9) production (e.g. minimum production required to open a plant); 10) routes (e.g. useable routes during each time period); 11) perishability (e.g. product's minimum remaining shelf life when being delivered).

\subsubsection{Model Application}

Two methods are normally used to validate the proposed models, namely a case study application or a real case application. A model can also be validated by applying both methods. A case study application consists in solving the proposed model by using simulated data. In real case applications, the used data are obtained from a real SC.

\subsection{Uncertainty Modelling}

This dimension comprises three categories: 1) the modelling context, where models are identified as being deterministic or uncertain; 2) uncertain parameters, where the existing sources of uncertainty in AFSC are identified; 3) type of uncertainty, where the different ways of modelling uncertainty are exposed. 


\subsubsection{Modelling Context}

When developing a mathematical programming model to support a decision-making process, it must first be decided if this model should either consider uncertainty sources (uncertain context) or ignore them (deterministic context). In order to develop models that accurately represent AFSC behaviour, the uncertainty sources that strongly impact AFSC performance should be modelled.

\subsubsection{Uncertain Parameters}

The existing sources of uncertainty in crop-based AFSC have been categorised by Esteso, Alemany and Ortiz (2017) by classifying them into four blocks depending on whether they are related to the product, process, market or environment. This categorisation is adapted to the whole AFSC by adding the "cost uncertainty" to process uncertainties, and by changing the "harvesting yield uncertainty" (which refers to crop-based AFSC) per "supply uncertainty" (in order to consider the different AFSC types):

- Product uncertainties: (i) product shelf-life; (ii) deterioration rate; (iii) product heterogeneity; (iv) food quality; (v) food safety uncertainties. Product shelf-life consists in the time during which a product can be consumed. Deterioration rate denotes a product's deterioration speed. Product heterogeneity refers to the difference of attributes between units of the same product. Food quality measures customer satisfaction and legal requirements. Food safety consists in assuring a product's non-contamination.

- Process uncertainties: (i) supply characteristics; (ii) lead time; (iii) resource needs; (iv) costs; (v) production uncertainties. Supply characteristics refer to the quantity, quality and arrival time of the supply. Lead time denotes the time needed to complete processes. Resource needs consists in the requirements of machines 
and labourers to follow processes. Costs are the unitary costs generated by each activity. Production uncertainty refers to the uncertainty produced by not knowing the real quantity and quality of ingredients when producing a final product.

- Market uncertainties: (i) demand; (ii) market prices uncertainties. Both these items are usually interrelated in the agri-food sector.

- Environment uncertainties: (i) weather; (ii) pests and diseases; (iii) regulations uncertainties. Weather uncertainty has a stronger impact on crop-based AFSC where product characteristics strongly depend on the weather. Pests and diseases are usually unpredictable and strongly influence product safety. Finally, changes in the regulations that deal with food quality and safety have a huge impact on AFSC and their content cannot be known in advance.

\subsubsection{Uncertainty Type}

In their review of perspectives of uncertainty, Samson, Reneke and Wiecek (2009) mainly identify two uncertainty types according to the grade of known information: epistemic and aleatory uncertainty.

Decisions are made under aleatory uncertainty when the possible consequences (or results) of such decisions are known. In addition, the probability of each consequence occurring is usually known or can be estimated before making decisions. Some approaches, such as SP, can be used to model this uncertainty type. In fact, the aleatory uncertainty and stochastic uncertainty concepts can be used interchangeably (Oberkampf et al. 2004).

Moreover, we fall within the scope of making a decision under epistemic uncertainty when the possible consequences for this decision are unknown and not even meaningful. Therefore, as we do not recognise the possible consequences, the probability 
of each one occurring is impossible to know. Some approaches, such as fuzzy set theories, can be employed for modelling epistemic uncertainty.

After identifying which uncertainty type better represents the real source of uncertainty present in an AFSC, the function that characterises the behaviour of the source of uncertainty should be selected. For example, aleatory uncertainty could be represented by a distribution function (normal distribution, Weibull distribution, etc.), while epistemic uncertainty could be represented by a membership function (trapezoidal function, triangular function, etc.).

\section{Analysing AFSC Design Models}

The proposed $\mathrm{CF}$ was used to analyse the existing mathematical programming models used to design an AFSC to validate it by establishing the current state of the art and identifying possible gaps in this research area.

The literature review was done by using the process proposed by Seuring and Müller (2008) to analyse content: 1) Material collection, where the material to be collected is defined and delimitated; 2) Descriptive analysis, where the material's formal aspects are assessed; 3) Category selection, where structural dimensions and related analytic categories are selected; 4) Material evaluation, where the material is analysed according to the structural dimensions and categories.

Material collection was carried out in well-known scientific databases (Google Scholar, Web of Science, Scopus, Elsevier, Emerald, Taylor \& Francis and Springer) using the following keywords:

- Agri-food supply chain

- Agro-food supply chain

- Food supply chain 
- Agriculture

- Supply chain design

- Network design

- Location

- Optimisation

- Operation research

- Mathematical programming

Although a vast amount of papers related to the proposed keywords were found, not all these publications proposed mathematical programming models to design AFSC. To identify the papers that dealt with this problem, two refining processes were conducted in each paper: 1) reading the title, abstract and keywords in order to eliminate those that did not focus on AFSC; 2) verifying the proposal of mathematical programming models that dealt with at least one of the SC design decisions proposed by Chopra and Meindl (2007). For this reason, some papers that modelled some of the main AFSC characteristics, such as Dellino et al. (2017), Huang and Song (2017), and Rong, Akkerman and Grunow (2011), but did not make decisions about SC design, were ruled out. Having finished the refining process, reference and citation analyses were done to find older and more recent contributions.

Finally, 30 papers needed to be further analysed, of which 22 were scientific journal publications, six were conference proceedings and two were book chapters (Table 2). References spanned 15 years, although $83 \%$ of the papers have been published in the last 6 years (Figure 2), which demonstrates the increasing interest of researchers in AFSC design through mathematical programming models.

[Table 2 near here]

[Figure 2 near here] 
The structural dimensions and categories employed to analyse the selected literature were those that comprise the proposed CF. The covering degree of each structural dimension allowed the current state of the art and future research lines to be identified.

The state of the art is structured as follows: firstly, the results obtained for each category that comprised the CF dimensions were analysed independently. Secondly, the relationship between the results obtained for each category that made up a dimension was established in an additional subsection called "Findings", which was included at the end of each dimension section (Subsections 3.1.5, 3.2.4, 3.3.5, and 3.4.4). For example, the "Findings" of "Uncertainty Modelling" established the relation among the results obtained in categories "Modelling Context", "Uncertain Parameters", and "Type of Uncertainty". Finally, a global literature analysis for all the dimensions and categories was carried out in the Conclusions section from which the main conclusions were drawn and gaps in the literature were identified.

\subsection{AFSC Characteristics}

This dimension provides an overview of the characteristics inherent to AFSC, which have been considered in previous models. The AFSC characteristics considered by each paper are analysed in Table 3.

[Table 3 near here]

\subsubsection{Subsector}

Most references (83\%) proposed generic AFSC models. This means that they can be applied to more than one product type (crop-based or animal-based products). Of these generic models, $72 \%$ were validated in potatoes (Accorsi et al. 2016), rice (Baghalian, Rezapour, and Farahani 2013), meat (Boudahri et al. 2011, 2012a, 2012b, 2013; 
Etemadnia et al. 2013; Mohammed and Wang 2017a, 2017b, 2017c), chocolate manufacturers (Colicchia et al. 2016), grains (Ding 2011, 2013), vegetables and fruits (Xiaohui and Wen 2009; Etemadnia et al. 2015), apples and by-products (Zhao and Dou 2011; Zhao and Lv 2011), or bakery (Villa-Marulanda, Leguizamón, and Niño-Mora 2010) SC.

Whereas $16.7 \%$ of the papers proposed models to design SC of a specific product, such as pea-based novel protein food (Apaiah and Hendrix 2005), sugar cane (Jonkman et al. 2017; Neungmatcha et al. 2013), or dairy products (Jouzdani, Sadjadi, and Fathian 2013; Wouda et al. 2002).

\subsubsection{Supply Chain Stages}

The most considered stages when designing AFSC were processor and retailer stages (73.3\%), followed by the distributor stage (53.3\%) and the supplier stage (46.7\%). Most models (96.7\%) took into account more than one SC stage when designing AFSC, and only one model designed a one-stage SC. It should be stressed that each stage could comprise one member or more, as in Apaiah and Hendrix (2005), where only the processor stage was considered by locating three different types of processing facilities.

The suppliers considered by models were mainly farmers (Allaoui et al. 2016; Ding 2011, 2013; Jouzdani, Sadjadi, and Fathian 2013; Mohammed and Wang 2017a, 2017b, 2017c; Zhao and Dou 2011; Zhao and Lv 2011). However, other models mentioned generic suppliers (Amorim et al. 2016) and the rest detailed type of farmers, such as sugar cane fields (Neungmatcha et al. 2013), crops (Accorsi et al. 2016), supply regions (Jonkman et al. 2017), or milk regions, defined as groups of farmers (Wouda et al. 2002). 
Some models considered the processor stage and included more than one facility type (20.0\% of the models). This is the case of Allaoui et al. (2016), who considered different types of processing facilities, and Ding (2011), who included grain elevators and final processors. Jouzdani, Sadjadi and Fathian (2013) considered processing factories and dairy manufacturers, while Neungmatcha et al. (2013) distinguished between sugar cane loading stations and mill factories. Zhao and Dou (2011) and Zhao and Lv (2011) included plants of semi-finished products and plants of finished products. All the other models referred to the processor stage when they mentioned packaging and processing plants (Accorsi et al. 2016), factories (Amorim et al. 2016; Ding 2013), processors (Apaiah and Hendrix 2005; Jonkman et al. 2017), manufacturers (Baghalian, Rezapour, and Farahani 2013; Govindan et al. 2014), production node/location (Etemadnia et al. 2013, 2015), production plants (Villa-Marulanda, Leguizamón, and Niño-Mora 2010; Wouda et al. 2002), slaughterhouses (Boudahri et al. 2011, 2012a, 2012b, 2013) or abattoirs (Mohammed and Wang 2017a, 2017b, 2017c).

When considering the distributor stage, some models referred to distribution centres (Allaoui et al. 2016; Baghalian, Rezapour, and Farahani 2013; Di et al. 2011; Govindan et al. 2014; Wouda et al. 2002; Xiaohui and Wen 2009; Zhi-lin and Dong 2007), warehouses (Accorsi et al. 2016; Reza-Nasiri and Davoudpour 2012; Singh et al. 2016), hubs (Etemadnia et al. 2013, 2015), regional sale markets (Zhao and Dou 2011; Zhao and Lv 2011), or a combination of a central warehouse and a set of transit points (Colicchia et al. 2016).

In the analysed papers, the authors referred to the retailer stage as retailers (Allaoui et al. 2016; Amorim et al. 2016; Baghalian, Rezapour, and Farahani 2013; Govindan et al. 2014; Mohammed and Wang 2017a, 2017b, 2017c), customer clusters, defined as a set of retailers (Boudahri et al. 2011, 2012a, 2012b, 2013), points of demand 
(Accorsi et al. 2016), delivery points (Colicchia et al. 2016), customer/consumer zone (Di et al. 2011; Reza-Nasiri and Davoudpour 2012), stores (Ding 2013), consumption nodes/locations (Etemadnia et al. 2013, 2015), customer points (Singh et al. 2016), demand points (Xiaohui and Wen 2009) or points of requirement (Zhi-lin and Dong 2007)

AFSC were designed by considering two stages in $46.7 \%$ of the models, where the interactions among supplier-processor (10.0\% of models), distributor-retailer $(20.0 \%$ of models), processor-retailer (13.3\% of models) or processor-distributor (3.3\% of models) were represented. Three-stage AFSC were designed in $43.3 \%$ of the models by considering these combinations: supplier-processor-retailer (20.0\% of the models), processor-distributor-retailer (13.3\% of the models) or supplier-processor-distributor (10.0\% of the models). Finally, $6.7 \%$ of the models designed AFSC by considering four stages: supplier, processor, distributor and retailer.

\subsubsection{Number of Products}

The models that considered a single product (60.0\%) were more commonplace than those that took into account multiple products (40.0\%), although this tendency has changed over the years.

Two ways to model multiple products were identified: 1) simultaneously managing different products in each process (e.g. apples and pears) (Allaoui et al. 2016; Baghalian, Rezapour, and Farahani 2013; Boudahri et al. 2012b, 2013; Reza-Nasiri and Davoudpour 2012; Singh et al. 2016) 2) differentiating between raw materials and processed products (Jouzdani, Sadjadi, and Fathian 2013). Some models considered both multiple products ways simultaneously (Amorim et al. 2016; Jonkman et al. 2017; Wouda et al. 2002; Zhao and Dou 2011; Zhao and Lv 2011). 
Real AFSC usually manage a wide variety of products that interact until the final product required by end customers is obtained. Thus in order to obtain more accurate AFSC design models that represent the real complexity of the agri-food sector, new models should simultaneously consider several products.

\subsubsection{Product Characteristics}

One of the most important characteristics of agri-food products is perishability, which was considered in $26.7 \%$ of the models by modelling the products' remaining shelf life after being produced (Amorim et al. 2016) or when reaching the retailer (Singh et al. 2016), the maximum consecutive time periods during which a product can be stored (Govindan et al. 2014), or a product's deterioration rate while being transported (Di et al. 2011; Xiaohui and Wen 2009; Zhao and Dou 2011; Zhao and Lv 2011; Zhi-Lin and Dong 2007) or stored (Di et al. 2011).

Food quality was modelled in two papers. Mohammed and Wang (2017b) considered food quality by maximising the healthiness of the livestock transported to slaughterhouses and the freshness of meat pieces transported from slaughterhouses to retailers. Amorim et al. (2016) considered this factor by assuming that local raw material was of better quality than non-local raw materials.

Product heterogeneity was modelled only in Amorim et al. (2016), where the combination of two raw material types determined the branding of final products (local or mainstream), which differentiated them in remaining shelf life, quality and price terms. Finally, food safety was not dealt with in any analysed model.

\subsubsection{Findings}

The results showed that more effort was required to develop SC design models to appropriately address agri-food sector characteristics Given the significant differences 
between animal-based and crop-based AFSC production processes, it is necessary to develop models to appropriately design these two SC types.

No model contemplated the customer stage when designing AFSC. This is reasonable since customers in the agri-food sector are responsible for buying demanded products at retailers. Thus retailers represent end customers' demand. However, in order to develop AFSC design models that represent the whole $\mathrm{SC}$, the supplier, processor, distributor and retailer stages should at least be considered.

Some agri-food products need to be processed to meet consumer requirements. For example, raw materials that need to be cut to obtain different end products (e.g. beef cut into chuck, rib, brisket), products composed of combining different raw materials (e.g. salad made of lettuce, tomato and carrot) or final products obtained by applying different cooking procedures to one same raw material (e.g. cream, buttermilk, and yoghurt made with milk). This shows the huge complexity that AFSC face when managing products. In order to accurately represent this complexity, AFSC design models should simultaneously take into account more than one product.

Finally, the analysed models did not appropriately address the product characteristics that strongly influenced AFSC performance, such as product perishability, food quality, food safety and product heterogeneity. Surprisingly, $63.3 \%$ of the models did not consider any inherent product characteristic of AFSC. Most of the models that addressed the product perishability characteristic did so in the AFSC that comprised more than one stage close to customers (regardless of the number of managed products). It is also noteworthy that food quality and heterogeneity characteristics were addressed in two models and one model, respectively, by considering the whole AFSC. Making the effort to develop models that address these last characteristics, even simultaneously, is highly recommended to ensure AFSC's good performance and efficiency. 


\subsection{Decisions Characteristics}

This section aims to identify the decisions made by each analysed model and the time horizon considered in them (Table 4).

[Table 4 near here]

\subsubsection{Design Decisions}

Almost all the reviewed models $(96.7 \%)$ decided the location of one facility or more, such as production plants (66.7\% of the models), distribution centres (43.3\% of the models), or retailers ( $6.6 \%$ of the models). In $16.7 \%$ of the models, the level of capacity allocated to each location was also defined.

The role that each facility was to play was decided in $23.3 \%$ of the references, with decisions such as the products to be produced in each plant (Allaoui et al. 2016; Jonkman et al. 2017; Zhao and Dou 2011; Zhao and Lv 2011), or the processes to be performed at each open location (Accorsi et al. 2016; Jonkman et al. 2017; Jouzdani, Sadjadi, and Fathian 2013; Wouda et al. 2002).

Once facilities had been opened, $6.7 \%$ of the models made the decision to maintain or close facilities during each time period depending on costs, emissions generated, water use, efficiency and employment created when opening, maintaining or closing a facility (Allaoui et al. 2016) or according to the costs of opening and closing locations (Singh et al. 2016).

The connections among different AFSC members were defined in all the models (100\%), of which $43.3 \%$ defined the suppliers that supplied each processor, $46.7 \%$ stated the existing relations among processors, distributors or processors-distributors, and $86.7 \%$ decided which distributors or processors were to serve each retailer. 


\subsubsection{Additional Decisions}

The most considered decision was transportation (63.3\% of models), for which the quantity to be transported between the supplier and the production plant $(36.7 \%)$, production plants $(40.0 \%)$, the plant and DC $(26.7 \%)$, DC and retailer $(23.3 \%)$ or, the production plant and the retailer $(20.0 \%)$ was decided. Only $23.3 \%$ of the models considered transportation of products over the whole AFSC (Accorsi et al. 2016; Allaoui et al. 2016; Amorim et al. 2016; Jonkman et al. 2017; Mohammed and Wang 2017a, $2017 \mathrm{~b}, 2017 \mathrm{c})$. In addition, $16.7 \%$ of the models defined the transport mode that was to be used depending on the related costs and/or environmental impact, and 3.3\% of them determined the vehicle to be used according to the required capacity.

The route to follow during distribution was defined in $10.0 \%$ of the models by choosing among several possible routes (Baghalian, Rezapour, and Farahani 2013), by defining the best route to minimise costs and the environmental impact (Govindan et al. 2014), or by solving a classical travelling salesman problem (Boudahri et al. 2013).

The amount of product to be manufactured at each facility was defined in $23.3 \%$ of the models. The quantity of raw material to be bought from suppliers was considered in $16.7 \%$ of the models. Among them, Amorim et al. (2016) also differentiated between the quantity to be produced with regular and overtime production.

In addition, one of these models decided which energy type to employ when processing a product according to generated emissions, and also to the water used by it (Allaoui et al. 2016).

The amount of products to store as inventory at all the facilities during each time period was defined in only $6.7 \%$ of the models. These models simultaneously represented product perishability using its remaining shelf life. In these cases, it was important to not only ensure that products did not exceed the maximum consecutive time periods during 
which a perishable product could be stored (Govindan et al. 2014), but to also be aware of the age of each stored product (Amorim et al. 2016).

The number of labourers needed at each facility to complete the involved processes requirements was defined in $6.7 \%$ of the models, where the working rates per labourers, their cost per hour, and the minimum required hours for contracting labourers were considered.

\subsubsection{Time Horizon}

The majority of the models (83.3\%) were developed to design AFSC by considering data from a single time period. Multiple period models (16.7\%) simultaneously contemplated strategic decisions about facilities and tactical/operational decisions, such as inventory, transport, procurement or production decisions.

As $66.7 \%$ of the models simultaneously addressed strategic, planning and/or operational decisions, and given some of the agri-food sector's time-dependent characteristics (e.g. product perishability), it would be logical to develop models to design AFSC that considered a multiple period horizon time. This could ensure that the obtained results would be more accurate in relation to real AFSC behaviour and performance.

Note that most of the models which considered product perishability, which is a time-dependent characteristic, contemplated a one-time period horizon. In these cases, perishability was modelled by a product deterioration rate during its transport (Di et al. 2011; Xiaohui and Wen 2009; Zhao and Dou 2011; Zhao and Lv 2011; Zhi-Lin and Dong 2007) and was employed to decide where to locate AFSC facilities because, if two facilities were far from one another, a product could deteriorate while being transported between them. Moreover, the models that considered product perishability in a multiple time periods horizon usually modelled it by contemplating a product's remaining shelf 
life during each time period (Amorim et al. 2016; Govindan et al. 2014). These models were the only ones that addressed inventory decisions, for which knowledge of a product's remaining shelf life is important.

\subsubsection{Findings}

The agri-food sector is under strong pressure to improve its resilience capabilities due to severe environmental conditions, government food safety regulations and the global market increasingly demanding requirements in product quality, variety and personalisation terms. And all this is to respond to abrupt changes in the quality, quantity and availability of resources, especially with unexpected environmental circumstances caused by existing uncertainty related to climate, pests and diseases, and also by volatile market conditions, prices of raw materials, etc.

In order to achieve rapid, flexible and efficient responsiveness, AFSC need to adopt integrated strategies from raw material production to product distribution to end customers in order to align demand and supply in the most competitive and dynamic way. Thus simultaneously solving design and tactical/operational decisions can improve AFSC performance in the long, mid, and short terms. Given the special features of AFSC, it would be interesting to develop models that address design, procurement, production, storage and transport decisions to obtain AFSC configurations capable of meeting market requirements in product freshness, quality, safety and homogeneity terms, while minimising product losses. This can only be possible by considering AFSC's inherent product characteristics.

Despite the need for flexible design solutions, we found from the literature review that most models used a single period approach to represent a static decision-making process, where decisions were made at one time horizon point. These decisions need to 
be respected during successive time periods by limiting subsequent tactical/operational decisions and determining future SC performance.

In order to obtain more flexible and adaptable AFSC, design decisions should be made dynamically. To this end, multiple time periods and design decisions allowing changes in SC configurations (e.g. opening, maintaining or closing facilities, and changing the allocation of processes/products to facilities, the capacity of facilities and the connections between facilities) should be considered during each time period depending on stakeholders' needs.

\subsection{Modelling Approach}

The objective of this section is to characterise the analysed models to identify their modelling type, model purpose, constraints and application. This analysis is useful to identify the commonest characteristics and the possible gaps in existing AFSC design models (Tables 5 and 6).

[Table 5 near here]

[Table6 near here]

\subsubsection{Model Type}

The most employed modelling type was MILP, which was used in 53.3\% of the analysed models, followed by MOILP and SP used by $13.3 \%$. The analysed stochastic models could, in turn, be categorised as either stochastic mixed integer linear programming (Amorim et al. 2016; Ding 2011, 2013) or multi-objective stochastic non-linear programming (Reza-Nasiri and Davoudpour 2012). Two LP models and one MONLP model were identified.

FMP was employed in $10.0 \%$ of the analysed models, although two types of FMP were identified: Fuzzy multi-objective integer linear programming (Mohammed and 
Wang 2017a, 2017c) and Fuzzy non-linear mixed integer programming (Jouzdani, Sadjadi, and Fathian 2013).

MILP models were NP-hard problems whose resolution proved to be timeconsuming and computationally intractable in medium-large problems (Zhao and Lv 2011). For this reason, $45 \%$ of the analysed references proposed a MILP model, and simultaneously presented algorithms/heuristics to solve the model in a reasonable time. Similarly, algorithms/heuristics were used to solve $57.1 \%$ of uncertain models.

In order to also cope with model complexity, $16.6 \%$ of the studied references (Allaoui et al. 2016; Amorim et al. 2016, Boudahri et al 2011, 2012a, 2012b) applied twostage optimisation techniques, where the entire problem was decomposed into two problems and each problem was sequentially solved. The result obtained in the first stage was used as input to solve the second stage.

It is also worth mentioning that two of the analysed papers employed the MOILP (Allaoui et al. 2016) and the multi-objective FMP (Mohammed and Wang 2017a) model types, along with multi-attribute decision-making (MADM) approaches to simultaneously consider multiple performance indicators in a simplified manner. MADM approaches were used to identify the best option from a limited number of alternatives whose attributes were known (Banasik et al. 2016). Allaoui et al. (2016) applied MADM techniques in a first step to assess potential partners from a limited set which, once selected, were taken as input in the second step for the MOILP model to decide the AFSC design. Mohammed and Wang (2017a) firstly proposed a fuzzy multi-objective model to design an AFSC, which provided them with limited Pareto-optimal solutions. Secondly, an MADM method was used to seek the best Pareto solution as a trade-off decision when optimising three conflicting objectives. 
Finally, Govindan et al. (2014) studied a two-echelon facility location problem, while Mohammed and Wang (2017c) developed a product distribution planner for a threeechelon green meat SC design.

\subsubsection{Model Purpose}

All models pursue economic objectives, and for $90.0 \%$ of the models this implies minimising costs and maximising profits for $10.0 \%$ of the models, while considering the dependence of price on product branding (Amorim et al. 2016) or season (Jonkman et al. 2017), or on markets (Baghalian et al. 2013). The costs accounted in each model are identified in Table 7, and the most widely used costs are related to the location of facilities (67\% of the models), production (47\% of the models) and transportation (100\% of the models). Other models represented the costs incurred by inventory $(23.3 \%)$, procurement (16.7\%), product waste (13.3\%), unmet demand (10.0\%), RFID uses (10.0\%), closing locations $(6.7 \%)$, energy use $(3.3 \%)$ or labouring $(3.3 \%)$. It is worth noting that very little attention was paid to minimising waste $(13.3 \%)$ when designing AFSC, despite it being an important source of inefficiencies.

The environmental aspect of sustainability was considered in $13.3 \%$ of the models. Allaoui et al. (2016) minimised the total produced $\mathrm{CO}_{2}$ emissions and the water used when locating and operating a facility, and also when transporting products. Colicchia et al. (2016) minimised $\mathrm{CO}_{2}$ emissions while transporting and storing products. Govindan et al. (2014) reduced the general environmental impact when transporting, producing and handling products, or when opening a facility. Mohammed and Wang (2017c) proposed minimising $\mathrm{CO}_{2}$ emissions when opening facilities and transporting products. Although Accorsi et al. (2016) and Boudhari et al. (2012a, 2013) did not consider any environmental impact-related objective, but assumed its minimisation by 
assigning a related cost to the whole chain. Carbon trading mechanisms can also be used by AFSC actors to minimize carbon emissions and to comply with carbon cap-and trade regulations (Wang, Zhao and Herty, 2018).

The social aspect of sustainability was addressed by $20.0 \%$ of the models. For this purpose, models aimed to minimise total delivery times (Mohammed and Wang 2017a, 2017c; Reza-Nasiri and Davoudpour 2012), maximise customer satisfaction, measured as the degree of demand fulfilment (Mohammed and Wang 2017b, 2017c), and maximise product quality (Mohammed and Wang 2017b), job creation (Allaoui et al. 2016) and the conditional value-at-risk of customer services (Amorim et al. 2016).

Thus according to the classification by Farahani et al. (2014), we found that $100 \%$ of the analysed models were designing Lean SC, $23.3 \%$ of the models designed Green AFSC and $6.67 \%$ of them designed Sustainable AFSC. Sustainability performance of AFSC could be analytically evaluated with methodologies such as the proposed by Yakovleva, Sarkis and Sloan (2012). For a recent review of quantitative models to address issues in sustainable food supply chains, see Zhu et al. (2018).

\subsubsection{Model Constraints}

The most widely considered constraint was the capacity limitation of facilities $(76.7 \%$ of the references), followed by supply constraints ( $36.7 \%$ of the models) that determine the maximum quantity to be provided from suppliers.

The constraints related to the number of locations to be opened $(20.0 \%$ of the models) referred to the maximum (Govindan et al. 2014; Neungmatcha et al. 2013; Wouda et al. 2002), the minimum (Ding 2011) or the exact number (Di et al. 2011; Xiaohui and Wen 2009) of locations to be opened. 
The maximum distance to be covered when transporting/distributing products was addressed in $16.7 \%$ of the models to ensure the proximity of AFSC members (Ding 2011, 2013), sales of local products (Etemadnia et al. 2013, 2015), or a minimum product's remaining shelf life when delivered to customers (Singh et al. 2016). In contrast, Colicchia et al. (2016) considered the minimum distance between opened locations to avoid the crossing replenishment flows from two locations.

Similarly, $16.7 \%$ of the models considered a time limitation; e.g. the maximum allowable time for transportation (Zhao and Dou 2011; Zhao and Lv 2011), the minimum working hours to contract labourers (Mohammed and Wang 2017a, 2017b) or considering time windows for deliveries (Govindan et al. 2014).

Other constraints covered by the models included considering existing routes to transport products (Baghalian, Rezapour, and Farahani 2013; Jouzdani, Sadjadi, and Fathian 2013), the maximum allowed budget to open locations (Baghalian, Rezapour, and Farahani 2013), the maximum flow of product to go through each facility (Zhi-lin and Dong 2007), the minimum service level to be ensured (Ding 2013) and the minimum production to open a new facility (Zhao and Dou 2011; Zhao and Lv 2011).

\subsubsection{Model Application}

The majority of analysed papers $(86.7 \%)$ validated their models and showed their applicability using a case study. Conversely, only $13.3 \%$ of the publications validated their models by applying them to a real AFSC.

\subsubsection{Findings}

This result of the dimension showed that many AFSC design models were MILP models, which are time-consuming and even computationally intractable in medium-large problems. Thus algorithms/heuristics are needed to solve these models in reasonable 
computing times. Algorithms/heuristics are also employed when models are extremely complex to solve due the vast amount of parameters, decision variables, objectives and/or constraints to be considered.

Only four models dealt with different objectives from the economical one, and only one simultaneously dealt with three sustainability dimensions. All these models used MOILP, and some combined it with multi-attribute decision-making techniques. Models for designing sustainable AFSC are needed, especially those that focus on the environmental and social dimensions, which can be respectively represented by reducing generated emissions and water/resource use, and by creating jobs. Given the conflicting nature of these dimensions and the necessity to include them in AFSC design processes, it would be appropriate to apply multi-objective programming and/or other modelling types combined with MADM approaches within multi-level optimisation frameworks.

The most modelled constraints were related to the capacity of facilities, available quantities at suppliers, times and distances. Some product characteristics-related constraints were lacking, such as products' minimum remaining shelf life needed in each SC stage, minimum food quality ensured at retailers, a constraint to ensure products' food safety, or a constraint to meet customer requirements in product homogeneity terms. Therefore, more effort needs to be made to develop models that consider constraints related to agri-food product characteristics.

Finally, more real applications of models are needed to identify the real benefits of considering specific AFSC characteristics when making decisions, e.g., designing SC.

\subsection{Uncertainty Modelling}

The aim of this section is to identify which uncertainty sources present in AFSC have been covered by existing design models, and how they have been dealt with (Table 8). 
[Table 8 near here]

\subsubsection{Modelling Context}

The majority of models did not consider any source of uncertainty when designing AFSC (73.3\% of the models). However, some other models contemplated at least one source of uncertainty. This was consistent with the model type employed by the authors who proposed uncertain models as they employed SP or FMP.

\subsubsection{Uncertain Parameters}

The most considered source of uncertainty was uncertainty on demand $(20.0 \%$ of the models), followed by uncertainty on supply and on costs (13.3\% of the models for each one). Uncertainty in supply was considered in the limitation of the quantity to be supplied (Amorim et al. 2016; Ding 2013; Mohammed and Wang 2017c), or when modelling possible disruptions in processors, distribution centres and retailers (Baghalian, Rezapour, and Farahani 2013). The costs considered to be uncertain in the analysed models included the cost of opening locations (Ding 2011, 2013), spot deal purchasing costs (Amorim et al. 2016), and transportation costs, RFID costs and handling costs (Mohammed and Wang 2017c). Finally, uncertainty on lead time was also considered (Amorim et al. 2016) specifically in the supply lead time.

\subsubsection{Uncertainty Type}

Only eight papers modelled at least one source of uncertainty for AFSC. Of these cases, $62.5 \%$ of the models considered aleatory uncertainty when assigning a probability function to uncertain parameters. Amorim et al. (2016) modelled the purchasing cost of raw material and the available quantity of raw materials as normal distribution functions, demand as a gamma distribution depending on product age, and the supplier lead time as 
exponential negative offset. Baghalian, Rezapour and Farahani (2013) considered that demand followed a normal distribution function, and that supply uncertainty was characterised by disruption probabilities for manufacturers. Ding $(2011,2013)$ employed normal distribution functions to model the quantity of grain sold by suppliers and the cost of opening locations. Reza-Nasiri and Davoudpour (2012) also modelled demand with a normal distribution function.

Epistemic uncertainty was considered by other models (37.5\%). For this reason, uncertain parameters were modelled as either triangular fuzzy numbers (Jouzdani, Sadjadi, and Fathian 2013) or trapezoidal membership functions (Mohammed and Wang 2017a, 2017c).

\subsubsection{Findings}

The results of this dimension showed that a few mathematical programming models dealt with sources of uncertainty when designing AFSC. In addition, the sources of uncertainty considered by the models were not specific of the agri-food sector, but actually existed in any SC type regardless of the sector. As far as we know, no AFSC design models exist that consider inherent uncertainty in both product characteristics and the environment. This is a very surprising finding and one that constitutes a wide gap in the literature.

The uncertainties inherent to AFSC cause major imbalance between supply and demand in terms of product varieties, quantities, qualities, customer requirements, times and prices. The mismanagement of such sources of uncertainty for AFSC can very negatively impact the quality, safety, sustainability and logistic efficiency of products and processes throughout the AFSC (Manzini and Accorsi 2013) and in waste.

Since sources of uncertainty negatively impact AFSC performance, future models should design AFSC in an uncertain context to obtain results that faithfully represent AFSC behaviour. To this end, a study on the influence of sources of uncertainties on 
AFSC performance is required. The best way to model each source of uncertainty should be identified (epistemic or aleatory uncertainty). After establishing the knowledge-base in this area, future models can use this information to evaluate what sources of uncertainty to cover when designing AFSC and how to model them.

AFSC design models are needed that consider sources of uncertainty related to the product (shelf life, deterioration rate, heterogeneity, food quality, food safety), process (resources needs, production), market (product price) and the environment (weather, pests, diseases, regulations).

\section{Conclusions and future research lines}

Lack of both CF to design AFSC by mathematical programming modelling and state-ofthe-art of mathematical programming models to design AFSC motivated this research. The objective of this paper was to fill these two gaps in the research literature.

For this purpose, firstly CF to design AFSC by mathematical programming models was proposed. This framework is composed of four blocks that describe the characteristics of both the problem under study and the mathematical programming models that can be used to address the problem. CF can be used as a tool to either analyse existing mathematical programming models to design AFSC or to develop new models that apply to specific situations. Then a complete existing state-of-the-art mathematical programming model to design AFSC was carried out with the proposed CF. This allowed the framework to be validated.

The analysis results showed that most existing models design generic AFSC without considering all SC stages. Very few took into account the existence of multiple products and the product characteristics that strongly influenced AFSC performance. During the decision process, most models simultaneously considered design and tactical/operational decisions by a single time period approach. Thus given the 
complexity of the addressed problems, some mathematical programming models needed to be solved by algorithms/heuristics or by multi-stage optimisation methods. Those models basically considered economic objectives, while some also considered optimising the chain's environmental or social impacts. Very little attention was paid to minimise waste (13.3\%) when designing AFSC. This is surprising knowing that food waste and losses is a major concern in AFSC, as reflected in FAO's (2017) future trends. Since waste originates mainly from perishability and food quality, once again these aspects demand more attention. Most models were validated by them being applied to a case study.

It is interesting to observe how the consideration of product characteristics is related to the purpose of the AFSC design model and to the related design decisions (Figure 3). Food quality and product heterogeneity are related to socio-economic objectives, which makes sense as these two characteristics can be associated easily with customers' perception of the product. Similarly, product perishability is related to economic, social, and environmental objectives because it is not only related to customers' perception of a product, but also to the quantity of waste generated through AFSC. When considering product characteristics, related decisions are also related mainly to the allocation of the connections between the different SC stakeholders.

[Figure 3 near here]

Generally, the complexity of models increases when considering one agri-food product characteristic or more, and algorithms/heuristics are often needed to solve these models (Figure 4). The cases which contemplate perishability, but do not use algorithms to solve the model, correspond to the models with few constraints and decisions, one time period, one objective and two SC stages. So they can be considered small problems

[Figure 4 near here] 
Very few papers considered sources of uncertainty in their models. In addition, the sources of uncertainty (supply, lead time, cost, demand) modelled in the analysed models were present in each SC, regardless of the sector, and did not make a considerable contribution to uncertainty modelling research in the agri-food sector. Despite the negative impact of uncertainties on AFSC performance, no models were found that included any uncertain parameter related with either product characteristics or the environment. Therefore, it is necessary to include these inherent AFSC sources of uncertainty to obtain a proper and more robust AFSC design.

Lastly from this state of the art, the following future research lines are presented. Firstly, there is a need to make a distinction in models for designing crop-based and animal-based AFSC because their production process and product characteristics are not the same. These models should at least consider the supplier, processor, distributor and retailer stages of the SC, the existence of multiple products (and/or subproducts) and the characteristics of these products (perishability, food quality, food safety and heterogeneity). It is noteworthy that, to the best of our knowledge, no AFSC design model has dealt with the food safety characteristic before.

It is also necessary to develop multiple time periods AFSC design models to reflect the dynamic characteristics of products (limited shelf life, deterioration, seasonality in prices, production yields, etc.) and the environment. Considering multiple time periods also allows design decisions to be made during each time period by allowing the SC to adapt to requirements at all times. All the design decisions should be addressed by these models, and it would be interesting to simultaneously address the procurement, production, storage and transport decisions and product characteristics to obtain accurate solutions to real AFSC performance. Inclusion of multiple objectives related to economic, environmental and social aspects seems mandatory if different sustainability dimensions 
are to be addressed. In doing so, and given their usual conflicting nature and the inherent complexity of AFSC, adopting multi-objective programming models might be suitable. Combining other mathematical programming models with MADM techniques also seems adequate to provide MADM with a limited number of AFSC design solutions (alternatives) to be evaluated by different criteria. This can be used also to simplify the AFSC design problem by previously using MADM techniques to consider some objectives and to rule out the worst solutions from part of the AFSC design.

Future models should design AFSC in an uncertain context. For this purpose, more research on sources of uncertainty is needed. We propose conducting a study of the degree of influence that each source of uncertainty has on AFSC performance, followed by identifying the best way to address each uncertainty source. The results of this research could help researchers to decide which sources of uncertainty to address in future AFSC design models.

Acknowledgements. The first author acknowledges the partial support of the Programme of Formation of University Professors of the Spanish Ministry of Education, Culture, and Sport (FPU15/03595), and the partial support of Project "Development of an integrated maturity model for agility, resilience and gender perspective in supply chains (MoMARGE). Application to the agricultural sector." Ref. GV/2017/025, funded by the Generalitat Valenciana. The other authors acknowledge the partial support of Project 691249, RUC-APS: Enhancing and implementing Knowledge based ICT solutions within high Risk and Uncertain Conditions for Agriculture Production Systems, funded by the EU under its funding scheme H2020-MSCARISE-2015”.

\section{References}

Accorsi, Riccardo, Susan Cholette, Riccardo Manzini, Chiara Pini, and Stefano Penazzi. 2016. “The Land-Network Problem: Ecosystem Carbon Balance in Planning 
Sustainable Agro-Food Supply Chains.” Journal of Cleaner Production 112 (January): 158-171. doi:10.1016/j.jclepro.2016.06.082

Ahumada, O., J.R. Villalobos. 2009. "Application of planning models in the agri-food supply chain: A Review.” European Journal of Operational Research 196: 1-20. doi:10.1016/j.ejor.2008.02.014.

Akkerman, Renzo, Poorya Farahani, and Martin Grunow. 2010. "Quality, Safety and Sustainability in Food Distribution: A Review of Quantitative Operations Management Approaches and Challenges." OR Spectrum 32(4): 863-904. doi:10.1007/s00291-010-0223-2.

Allaoui, Hamid, Yuhan Guo, Alok Choudahri, and Jacqueline Bloemhof. 2016. "Sustainable Agro-Food Supply Chain Design Using Two-Stage Hybrid MultiObjective Decision-Making Approach.” Computers \& Operations Research, December. doi:10.1016/j.cor.2016.10.012

Amorim, Pedro, Eduardo Curcio, Bernardo Almada-Lobo, Ana P.F.D. Barbosa-Póvoa, and Ignacio E. Grossmann. 2016. "Supplier Selection in the Processed Food Industry under Uncertainty.” European Journal of Operational Research 252(3): 801-814. doi:10.1016/j.ejor.2016.02.005.

Apaiah, Radhika K., and Eligius M.T. Hendrix. 2005. "Design of a Supply Chain Network for Pea-Based Novel Protein Foods." Journal of Food Engineering 70(3): 383-391. doi:10.1016/j.jfoodeng.2004.02.043.

Baghalian, Atefeh, Shabman Rezapour, and Reza Zanjirani Farahani. 2013. "Robust Supply Chain Network Design with Service Level against Disruptions and Demand Uncertainties: A Real-Life Case.” European Journal of Operational Research 227(1): 199-215. doi:10.1016/j.ejor.2012.12.017. 
Banasik, Aleksander, Jacqueline M. Bloemhof-Ruwaard, Argyris Kanellopoulos, G.D.H. Claassen, and Jack G.A.J. van der Vorst. 2016. "Multi-Criteria Decision Making Approaches for Green Supply Chains: A Review." Flexible Services and Manufacturing Journal, November. doi:10.1007/s10696-016-9263-5.

Borodin, Valeria, Jean Bourtembourg, Faicel Hnaien, and Nacima Labadie. 2016. "Handling Uncertainty in Agricultural Supply Chain Management: A State of the Art." European Journal of Operational Research 254 (2): 348-59. doi:10.1016/j.ejor.2016.03.057.

Boudahri, Fethi, Wassila Aggoune-Mtalaa, Mohammed Bennekrouf, and Zaki Sari. 2013. “Application of a Clustering Based Location-Routing Model to a Real Agri-Food Supply Chain Redesign.” In Advanced Methods for Computational Collective Intelligence, edited by Ngoc Thanh Nguyen, Bogdan Trawiński, Radoslaw Katarzyniak, and Geun-Sik Jo, 457:323-331. Berlin, Heidelberg: Springer Berlin Heidelberg. doi: 10.1007/978-3-642-34300-1_31.

Boudahri, Fethi, Mohamed Bennekrouf, Fayçal Belkaid, and Zaki Sari. 2012a. “Application of a Capacitated Centered Clustering Problem for Design of AgriFood Supply Chain Network.” International Journal of Computer Science Issues 9(4): 300-304.

Boudahri, Fethi, Mohamed Bennekrouf, Fayçal Belkaid, and Zaki Sari. 2012b. "Reconfiguration of the Real Agri-Food Supply Chain with a Subcontractor to Accommodate Electronic Technology." In Advances in Mechanical and Electronic Engineering, edited by David Jin and Sally Lin, 177:551-556. Berlin, Heidelberg: Springer Berlin Heidelberg. doi:10.1007/978-3-642-31516-9_88

Boudahri, Fethi, Zaki Sari, Fouad Maliki, and Mohammed Bennekrouf. 2011. "Design and Optimization of the Supply Chain of Agri-Foods: Application Distribution 
Network of Chicken Meat." In 2011 International Conference on Communications, Computing and Control Applications, 1-6. IEEE. doi:10.1109/CCCA.2011.6031424.

Chopra, Sunil, and Peter Meindl, 2007. Supply Chain Management: Strategy, Planning, and Operation. Third Edition. Upper Saddle River, New Jersey: Pearson Prentice Hall.

Colicchia, Claudia, Alessandro Creazza, Fabrizio Dallari, and Marco Melacini. 2016. "Eco-Efficient Supply Chain Networks: Development of a Design Framework and Application to a Real Case Study.” Production Planning \& Control 27(3): 157-68. doi:10.1080/09537287.2015.1090030.

Dellino, Gabriella, Teresa Laudadio, Renato Mari, Nicola Mastronardi, and Carlo Meloni. 2017. “A Reliable Decision Support System for Fresh Food Supply Chain Management." International Journal of Production Research. doi:10/1080.00207543.2017.1367106

Di, Weimin, Jinfeng Wang, Bingjun Li, and Meijie Wang. 2011. “A Location-Inventory Model for Perishable Agricultural Product Distribution Centers." In 2nd International Conference on Artificial Intelligence, Management Science and Electronic Commerce, 919-22. IEEE.

Ding, Si Bo. 2011. “ $\alpha$-Cost Minimization Model of Grain Supply Chain.” Key Engineering $\quad$ Materials $\quad 474-476 \quad$ (April): $\quad 50-53$. doi:10.4028/www.scientific.net/KEM.474-476.50.

Ding, Si Bo 2013. “A New Uncertain Programming Model for Grain Supply Chain Design.”Information (Japan) 16(2A): 1069-75. 
Esteso, Ana, M.M.E. Alemany, and Angel Ortiz. In press. "Analysis of OR-Based Literature Reviews on Agri-Food Supply Chains." In International Joint Conference - ICIEOM-ADINGOR-IISE-AIM-ASEM. Valencia, Spain.

Esteso, Ana, M.M.E. Alemany, and Angel Ortiz. 2017. "Conceptual Framework for Managing Uncertainty in a Collaborative Agri-Food Supply Chain Context.” IFIP Advances in Information and Communication Technology 506: 715-724. doi:10.1007/978-3-319-65151-4_64

Etemadnia, Hamideh, Stephan J. Goetz, Patrick Canning, and Mohammad Sadegh Tavallali. 2015. "Optimal Wholesale Facilities Location within the Fruit and Vegetables Supply Chain with Bimodal Transportation Options: An LP-MIP Heuristic Approach.” European Journal of Operational Research 244(2): 64861. doi:10.1016/j.ejor.2015.01.044.

Etemadnia, Hamideh, Ahmed Hassan, Stephan Goetz, and Khaled Abdelghany. 2013. "Wholesale Hub Locations in Food Supply Chains." Transportation Research Record: Journal of the Transportation Research Board 2379 (December): 80-89. doi:10.3141/2379-10.

Farahani, Reza Zanjirani, Shabnam Rezapour, Tammy Drezner, and Samira Fallah. 2014. "Competitive Supply Chain Network Design: An Overview of Classifications, Models, Solution Techniques and Applications.” Omega 45 (June): 92-118. doi:10.1016/j.omega.2013.08.006

FoodDrink Europe. 2016. Data \& Trends of the European Food and Drink Industry 2016. www.fooddrinkeurope.eu/publication/data-trends-of-the-european-foodand-drink-industry-2016/

Grillo, H., M.M.E. Alemany, A. Ortiz. 2016. “A Review of Mathematical Models for Supporting the Order Promising Process under Lack of Homogeneity in Product 
and other Sources of Uncertainty." Computers \& Industrial Engineering 91: 239-261. doi:10.1016/j.cie.2015.11.013

Grillo, H., M.M.E. Alemay, A. Ortiz, and V.S. Fuertes-Miquel. 2017. "Mathematical Modelling of the Order-Promising Process for Fruit Supply Chains Considering the Perishability and Subtypes of Products." Applied Mathematical Modelling 49: 255-78. doi:10.1016/j.apm.2017.04.037

Govindan, K., A. Jafarian, R. Khodaverdi, and K. Devika. 2014. “Two-Echelon MultipleVehicle Location-routing Problem with Time Windows for Optimization of Sustainable Supply Chain Network of Perishable Food.” International Journal of Production Economics 152 (June): 9-28. doi:10.1016/j.ijpe.2013.12.028.

Hobbs, Jill E., and Linda M. Young. 2000. "Closer Vertical Co-ordination in Agri-Food Supply Chains: A Conceptual Framework and Some Preliminary Evidence.” Supply Chain Management: An International Journal 5(3): 131-143. doi:10.1108/13598540010338884.

Huang, Jingsi, and Jie Song. 2017. "Optimal Inventory Control with Sequential Online Auction in Agriculture Supply Chain: An Agent-Based Simulation Optimisation Approach." International Journal of Production Research. doi:10.1080/00207543.2017.1373203

Iakovou, Eleftherios, Dimitrios Vlachos, Charisios Achillas, and Foivos Anastasiadis. 2012. "A Methodological Framework for the Design of Green Supply Chains for the Agrifood Sector." In The $2^{\text {nd }}$ International Conference on Supply Chains, Greece. Vol. 184.

Jonkman, Jochem, Jacqueline M. Bloemhof, Jack G.A.J. van der Vorst, and Albert van der Padt. 2017. "Selecting Food Process Designs from a Supply Chain 
Perspective." Journal of Food Engineering 195 (February): 52-60. doi:10.1016/j.jfoodeng.2016.09.015.

Jouzdani, Javid, Seyed Jafar Sadjadi, and Mohammad Fathian. 2013. "Dynamic Dairy

Facility Location and Supply Chain Planning under Traffic Congestion and

Demand Uncertainty: A Case Study of Tehran.” Applied Mathematical

Modelling 37(18-19): 8467-83. doi:10.1016/j.apm.2013.03.059.

Keizer, Marlies de, Rene Haijema, Jack van der Vorst, and Jacqueline BloemhofRuwaard. 2012. "Hybrid Simulation and Optimization Approach to Design and Control Fresh Product Networks." In Proceedings of the Winter Simulation Conference, 102. Winter Simulation Conference.

Keizer, Marlies de, Jack van der Vorst, J.M. Bloemhof, and R. Haijema. 2015. "Floricultural Supply Chain Network Design and Control: Industry Needs and Modelling Challenges.” Journal on Chain and Network Science 15 (1): 61-81. doi:10.3920/JCNS2014.0001.

Li, Dong, and Xiaojun Wang. 2017. "Dynamic Supply Chain Decisions Based on Networked Sensor Data: An Application in the Chilled Food Retail Chain". International Journal of Production Research. doi: $10.1080 / 00207543.2015 .1047976$

Lucas, M.T., and D. Chhajed. 2004. “Applications of Location Analysis in Agriculture: A Survey." Journal of the Operational Research Society 55(6): 561-578. doi:10.1057/palgrave.jors.2601731.

Manzini, Riccardo, and Riccardo Accorsi. 2013. "The New Conceptual Framework for Food Supply Chain Assessment.” Journal of Food Engineering 115(2): 251-63. doi: 10.1016/j.jfoodeng.2012.10.026. 
Melo, M.T., S. Nickel, and F. Saldanha-da-Gama. 2009. "Facility Location and Supply Chain Management - A Review." European Journal of Operational Research 196(2): 401-412. doi:10.1016/j.ejor.2008.05.007.

Meneghetti, Antonella, and Luca Monti. 2015. "Greening the Food Supply Chain: An Optimisation Model for Sustainable Design of Refrigerated Automated Warehouses.” International Journal of Production Research 53(21): 6567-6587. doi:10/1080.00207543.2014.985449.

Mohammed, Ahmed, and Qian Wang. 2017c. "The Fuzzy Multi-Objective Distribution Planner for a Green Meat Supply Chain.” International Journal of Production Economics 184 (February): 47-58. doi:10.1016/j.ijpe.2016.11.016.

Mohammed, Ahmed, and Qian Wang. 2017a. "Developing a Meat Supply Chain Network Design Using a Multi-Objective Possibilistic Programming Approach.” British Food Journal 119(3): 690-706. doi:10.1108/BFJ-10-2016-0475.

Mohammed, Ahmed, and Qian Wang. 2017b. "Multi-Criteria Optimization for a CostEffective Design of an RFID-Based Meat Supply Chain.” British Food Journal 119(3): 676-89. doi:10.1108/BFJ-03-2016-0122.

Monforti-Ferrario, F., J.-F. Dallemand, I.P. Pascua, V. Motola, M. Banja, N. Scarlat, H. Medarac, et al. 2015. "Energy Use in the EU Food Sector: State of Play and Opportunities for Improvement.” JRC Science and Policy Report. European Commission: Luxembourg.

Mula, Josefa, David Peidro, Manuel Díaz-Mandroñero, and Eduardo Vicens. 2010. "Mathematical Programming Models for Supply Chain Production and Transport Planning.” European Journal of Operational Research 204(3): 377-390. doi:10.1016/j.ejor.2009.09.008. 
Nakandala, Dilupa, Henry Lau, and Li Zhao. 2017. "Development of a Hybrid Fresh Food Supply Chain Risk Assessment Model." International Journal of Production Research 55(14): 4180-4195. doi:10.1080/00207543.2016.1267413

Neungmatcha, Woraya, Kanchana Sethanan, Mitsuo Gen, and Somnuk Theerakulpisut. 2013. “Adaptive Genetic Algorithm for Solving Sugarcane Loading Stations with Multi-Facility Services Problem.” Computers and Electronics in Agriculture 98 (October): 85-99. doi:10.1016/j.compag.2013.07.016.

Oberkampf, William L., Jon C. Helton, Cliff A. Joslyn, Steven F. Wojtkiewicz, and Scott Ferson. 2004. "Challenge Problems: Uncertainty in System Response given Uncertain Parameters.” Reliability Engineering \& System Safety 85(1-3): 11-19. doi:10.1016/j.ress.2004.03.002

Reza-Nasiri, G., and Hamid Davoudpour. 2012. "Coordinated Location, Distribution and Inventory Decisions in Supply Chain Network Design: A Multi-Objective Approach.” The South African Journal of Industrial Engineering 23(2): 159-75. doi:10.7166/23-2-338.

Rong, Aiying, Renzo Akkerman, and Martin Grunow. 2011. “An Optimization Approach for Managing Fresh Food Quality throughout the Supply Chain.” International Journal of Production Economics 131(1): 421-29. doi:10.1016/j.ijpe.2009.11.026

Samson, Sundeep, James A. Reneke, and Margaret M. Wiecek. 2009. "A Review of Different Perspectives on Uncertainty and Risk and an Alternative Modeling Paradigm." Reliability Engineering \& System Safety 94(2): 558-567. doi:10.1016/j.ress.2008.06.004

Sanabria Coronado, Lizeth Andrea, Andrés Mauricio Peralta Lozano, and Javier Arturo Orjuela Castro. 2017. "Modelos de Localización para Cadenas Agroalimentarias Perecederas: Una Revisión al Estado del Arte.” Ingeniería 22(1). 
Seuring, Stefan, and Martin Müller. 2008. "From a Literature Review to a Conceptual Framework for Sustainable Supply Chain Management.” Journal of Cleaner Production 16(15): 1699-1710. doi:10.1016/j.jclepro.2008.04.020.

Singh, Adarsh Kumar, Nachiappan Subramanian, Kulwant Singh Pawar, and Ruibin Bai. 2016. "Cold Chain Configuration Design: Location-Allocation Decision-Making Using Coordination, Value Deterioration, and Big Data Approximation.” Annals of Operations Research, October. doi:10.1007/s10479-016-2332-z.

Soto-Silva, Wladimir E., Esteve Nadal-Roig, Marcela C. González-Araya, and Lluis M. Pla-Aragones. 2016. “Operational Research Models Applied to the Fresh Fruit Supply Chain.” European Journal of Operational Research 251(2): 345-345. doi:10.1016/j.ejor.2015.08.046.

Tsiakis, P., N. Shah, and C.C. Pantelides. 2001. "Design of Multi-Echelon Supply Chain Networks under Demand Uncertainty." Industrial \& Engineering Chemistry Research 40(16): 3585-3604. doi:10.1021/ie0100030.

Tsolakis, N.K., C.A. Keramydas, A.K. Toka, D.A. Aidonis, and E.T. Iakovou. 2014. “Agrifood Supply Chain Management: A Comprehensive Hierarchical DecisionMaking Framework and a Critical Taxonomy." Biosystems Engineering 120: 4764. doi:10.1016/j.biosystemseng.2013.10.014.

Villa-Marulanda, Marcela, Gabriela Inés Leguizamón, and Karen Yineth Niño-Mora. 2010. “Solución Al Problema de Localización (CFLP) a Través de Búsqueda Tabú Y Relajación Lagrangeana, Caso de Estudio: Industria de Productos Alimentarios." Revista PUENTE Científica 4(2).

Vlajic, Jelena V., Jack G.A.J. van der Vorst, and René Haijema. 2012. “A Framework for Designing Robust Food Supply Chains.” International Journal of Production Economics 137(1): 176-189. doi:10.1016/j.ijpe.2011.11.026. 
Wang, Min, Lindu Zhao, and Michael Herty. 2018. "Modelling Carbon Trading and Refrigerated Logistics Services Within a Fresh Food Supply Chain Under Carbon Cap-and-Trade Regulation." International Journal of Production Research. doi:10.1080/00207543.2018.1430904.

Wouda, Francisca H.E., Paul van Beek, Jack G.A. J. van der Vorst, and Heiko Tacke. 2002. "An Application of Mixed-Integer Linear Programming Models on the Redesign of the Supply Network of Nutricia Dairy \& Drinks Group in Hungary.” OR Spectrum 24(4): 449-65. doi:10.1007/s002910200112.

Xiaohui, Qu, and Yuan Wen. 2009. "Studies on Spatio-Temporal Collaboration Model for Location Analysis of Vegetable and Fruit Logistics.” In Sixth International Conference on Fuzzy Systems and Knowledge Discovery, 619-26. Tianjin, China: IEEE. doi:10.1109/FSKD.2009.198.

Yakovleva, Natalia, Joseph Sarkis, and Thomas Sloan. 2012. "Sustainable Benchmarking of Supply Chains: The Case of the Food Industry." International Journal of Production Research 50(5): 1297-1317. doi:10.1080/00207543.2011.571926

Zhao, Xia, and Jianping Dou. 2011. "A Hybrid Particle Swarm Optimization Approach for Design of Agri-Food Supply Chain Network." In 2011 IEEE International Conference on Service Operations, Logistics, and Informatics, 162-167. Beijing, China: IEEE. doi:10.1109/SOLI.2011.5986548.

Zhao, Xia, and Qi Lv. 2011. “Optimal Design of Agri-Food Chain Network: An Improved Particle Swarm Optimization Approach.” In 2011 International Conference on Management and Service Science, 1-5. Wuhan, China: IEEE. doi:10.1109/ICMSS.2011.5998308. 
Zhang, Xiaoyong, and Lusine H. Aramyan. 2009. "A Conceptual Framework for Supply Chain Governance: An Application to Agri-food Chains in China." China Agricultural Economic Review 1(2): 136-54. doi:10.1108/17561370910927408.

Zhi-lin, Suo, and Wang Dong. 2007. "Location Model of Agricultural Product Distribution Center.” In International Conference on Management Science and Engineering, 1384-89. Harbin, China: IEEE. doi:10.1109/ICMSE.2007.4422038. Zhu, Zhanguo, Feng Chu, Alexandre Dolgui, Chengbin Chu, Wei Zhou, and Selwyn Piramuthu. 2018. "Recent Advances and Opportunities in Sustainable Food Supply Chain: A Model-Oriented Review.” International Journal of Production Research. doi:10.1080/00207543.2018.1425014 


\begin{tabular}{|c|c|c|c|c|c|}
\hline $\begin{array}{l}\text { Paper } \\
\text { type }\end{array}$ & Reference & Application & Dimensions & Novelty & Conclusions \\
\hline \multirow[t]{3}{*}{$\mathrm{CF}$} & $\begin{array}{l}\text { De Keizer et al. } \\
(2012)\end{array}$ & $\begin{array}{l}\text { Assessing the suitability of a } \\
\text { combined stochastic and dynamic } \\
\text { modelling approach to design and } \\
\text { control a responsive fresh product } \\
\text { SC network. }\end{array}$ & $\begin{array}{l}\text { System characteristics } \\
\text { Context factors } \\
\text { Performance indicators }\end{array}$ & $\begin{array}{l}\text { It considers the importance } \\
\text { of product perishability and } \\
\text { supply and demand } \\
\text { uncertainties during the SC } \\
\text { design process. }\end{array}$ & $\begin{array}{l}\text { Need to incorporate product perishability into both } \\
\text { design and control models. } \\
\text { A hybrid approach that combines simulation and } \\
\text { optimisation is a promising research direction. }\end{array}$ \\
\hline & $\begin{array}{l}\text { Iakovou et al. } \\
\text { (2012) }\end{array}$ & $\begin{array}{l}\text { Optimising the design, planning } \\
\text { and operation of AFSC by } \\
\text { implementing appropriate green SC } \\
\text { management and logistics } \\
\text { principles. } \\
\text { Tool for reducing } \mathrm{CO}_{2} \text { emissions } \\
\text { through the design, planning and } \\
\text { operation of AFSC. }\end{array}$ & $\begin{array}{l}\text { Sustainable farming } \\
\text { Supply chain management } \\
\text { Marketing } \\
\text { Environmental management } \\
\text { Reverse logistics } \\
\text { Corporate social responsibility }\end{array}$ & $\begin{array}{l}\text { This CF measures SC } \\
\text { performance by focusing } \\
\text { on environmental } \\
\text { performance, while } \\
\text { previous literature focuses } \\
\text { on efficiency and other } \\
\text { economic-related } \\
\text { performance. }\end{array}$ & $\begin{array}{l}\text { The proposed framework is expected to foster } \\
\text { sustainable regional socio-economic development on two } \\
\text { major axes, namely rural development and the } \\
\text { agriculture sector. } \\
\text { CF focus on developing green operations that will lead to } \\
\text { new environmentally benign SC designs and operations } \\
\text { to replace less sustainable practices. }\end{array}$ \\
\hline & $\begin{array}{l}\text { Vlajic, van der } \\
\text { Vorst, and } \\
\text { Haijema (2012) }\end{array}$ & $\begin{array}{l}\text { To support the analysis and design } \\
\text { of robust food SC. } \\
\text { Tool guide for managing process } \\
\text { disturbances and designing robust } \\
\text { SC. }\end{array}$ & $\begin{array}{l}\text { Description of the SC scenario and } \\
\text { identification of KPIs. } \\
\text { Identification and characterisation of } \\
\text { unexpected events and disturbances in } \\
\text { processes that impact performance } \\
\text { robustness. } \\
\text { Assessment of performance robustness } \\
\text { Identification of sources of vulnerability } \\
\text { Identification of appropriate redesign } \\
\text { principles and strategies. }\end{array}$ & $\begin{array}{l}\text { This CF fills the gap } \\
\text { caused by lack of an } \\
\text { integral framework that } \\
\text { guides companies to } \\
\text { manage process } \\
\text { disturbances and design } \\
\text { robust SC. }\end{array}$ & $\begin{array}{l}\text { Process disturbances can be detected and typified by } \\
\text { analysing the performance robustness of specific } \\
\text { scenarios. Each disturbance is related to a set of sources } \\
\text { of vulnerability that represent a direct/indirect cause of } \\
\text { disturbance. A set of redesign principles and strategies is } \\
\text { identified to prevent disturbance. More research is } \\
\text { needed to extend and validate these findings. } \\
\text { More research that models and quantifies the impact on } \\
\text { key SC performance indicators for alternative SC } \\
\text { scenarios is needed. }\end{array}$ \\
\hline \multirow[t]{2}{*}{ LR } & $\begin{array}{l}\text { Lucas and } \\
\text { Chhajed (2004) }\end{array}$ & $\begin{array}{l}\text { Bringing location-allocation } \\
\text { applications in agriculture to the } \\
\text { forefront. }\end{array}$ & $\begin{array}{l}\text { Product type } \\
\text { Model description } \\
\text { Model type } \\
\text { Solution procedure } \\
\text { Special features }\end{array}$ & $\begin{array}{l}\text { First review of applications } \\
\text { of location models in the } \\
\text { agriculture sector. }\end{array}$ & $\begin{array}{l}\text { Production-distribution models have emerged in agri- } \\
\text { business and authors expect them to continue. } \\
\text { It is important to consider globalisation and sources of } \\
\text { uncertainty when designing any global SC. Global SC } \\
\text { models should surface. }\end{array}$ \\
\hline & $\begin{array}{l}\text { Sanabria- } \\
\text { Coronado, } \\
\text { Peralta-Lozano, } \\
\text { and Orjuela- } \\
\text { Castro (2017) }\end{array}$ & $\begin{array}{l}\text { Establishing a generic state of the } \\
\text { art in AFSC location problems } \\
\text { related to mathematical } \\
\text { programming models. }\end{array}$ & $\begin{array}{l}\text { Type of location problem } \\
\text { Type of mathematical programming } \\
\text { model } \\
\text { Type of solution method } \\
\text { Aspects covered by papers }\end{array}$ & $\begin{array}{l}\text { Up-to-date review of AFSC } \\
\text { location models. }\end{array}$ & $\begin{array}{l}\text { Models including product perishability, waste and the } \\
\text { stochastic behaviour of some variables are required. } \\
\text { Dynamic models should be employed to locate facilities } \\
\text { in perishable AFSC. } \\
\text { Future models should contemplate different transport } \\
\text { types that allow the organoleptic properties of products } \\
\text { to be conserved. }\end{array}$ \\
\hline
\end{tabular}


Table 2. Number of publications per source

\begin{tabular}{lcc} 
Source & References & $\%$ \\
& & 1 \\
\hline Advanced Methods for Computational Collective Intelligence & 1 & 3.3 \\
Advances in Mechanical and Electronic Engineering & 1 & 3.3 \\
Annals of Operations Research & 1 & 3.3 \\
Applied Mathematical Modelling & 2 & 6.7 \\
British Food Journal & 1 & 3.3 \\
Computers \& Operations Research & 1 & 3.3 \\
Computers and Electronics in Agriculture & 3 & 10.0 \\
European Journal of Operational Research & 1 & 3.3 \\
Information & 1 & 3.3 \\
International Conference on Management Science and Engineering & 3.3 \\
International Conference on Fuzzy Systems and Knowledge Discovery & 1 & 3.3 \\
International conference on Service Operations, Logistics, and Informatics & 1 & 3.3 \\
International Conference on Communications, Computing and Control Applications & 1 & 3.3 \\
International Conference on Management and Service Science & 1 & 3.3 \\
International Conference on Artificial Intelligence, Management Science and Electronic & 1 & \\
Commerce & & 3.3 \\
International Journal of Computer Science Issues & 1 & 6.7 \\
International Journal of Production Economics & 2 & 3.3 \\
Journal of Cleaner Production & 1 & 2 \\
Journal of Food Engineering & 1 & 6.7 \\
Key Engineering Materials & 1 & 3.3 \\
OR Spectrum & 1 & 3.3 \\
Production Planning \& Control & 1 & 3.3 \\
Puente Revista Científica & 1 & 3.3 \\
South African Journal of Industrial Engineering & 1 & 3.3 \\
Transportation Research Record: Journal of the Transportation Research Board & 30 & 3.3 \\
\hline TOTAL & & 100 \\
\hline
\end{tabular}


Table 3. Classification of AFSC characteristics

\begin{tabular}{|c|c|c|c|c|c|c|c|c|c|c|c|c|}
\hline \multirow[b]{2}{*}{ Reference } & \multirow[b]{2}{*}{ Subsector } & \multicolumn{2}{|l|}{ SC stages } & \multirow[b]{2}{*}{ Distributor } & \multirow[b]{2}{*}{ Retailer } & \multirow[b]{2}{*}{ Customer } & \multicolumn{2}{|c|}{ No. of products } & \multicolumn{2}{|c|}{ Product characteristics } & \multirow[b]{2}{*}{$\begin{array}{l}\text { Food } \\
\text { safety }\end{array}$} & \multirow[b]{2}{*}{ Heterogeneity } \\
\hline & & Supplier & Processor & & & & One & Multiple & Perishability & $\begin{array}{c}\text { Food } \\
\text { quality }\end{array}$ & & \\
\hline Accorsi et al. (2016) & agri-food & $\mathrm{X}$ & $\mathrm{X}$ & $\mathrm{X}$ & $\mathrm{X}$ & & $\mathrm{X}$ & & & & & \\
\hline Allaoui et al. (2016) & agri-food & $\mathrm{X}$ & $\mathrm{X}$ & $\mathrm{X}$ & $\mathrm{X}$ & & & $\mathrm{X}$ & & & & \\
\hline Amorim et al. (2016) & agri-food & $\mathrm{X}$ & $\mathrm{X}$ & & $\mathrm{X}$ & & & $\mathrm{X}$ & $\mathrm{X}$ & $\mathrm{X}$ & & $X$ \\
\hline Apaiah and Hendrix (2005) & $\begin{array}{l}\text { pea-based } \\
\text { food }\end{array}$ & & $\mathrm{X}$ & & & & $\mathrm{X}$ & & & & & \\
\hline Baghalian, Rezapour, and Farahani (2013) & agri-food & & $\mathrm{X}$ & $X$ & $\mathrm{X}$ & & & $\mathrm{X}$ & & & & \\
\hline Boudahri et al. (2011) & agri-food & & $\mathrm{X}$ & & $\mathrm{X}$ & & $\mathrm{X}$ & & & & & \\
\hline Boudahri et al. (2012a) & agri-food & & $\mathrm{X}$ & & $\mathrm{X}$ & & $\mathrm{X}$ & & & & & \\
\hline Boudahri et al. (2012b) & agri-food & & $\mathrm{X}$ & & $\mathrm{X}$ & & & $\mathrm{X}$ & & & & \\
\hline Boudahri et al. (2013) & agri-food & & $\mathrm{X}$ & & $\mathrm{X}$ & & & $\mathrm{X}$ & & & & \\
\hline Colicchia et al. (2016) & agri-food & & & $\mathrm{X}$ & $\mathrm{X}$ & & $\mathrm{X}$ & & & & & \\
\hline Di et al. (2011) & agri-food & & & $\mathrm{X}$ & $\mathrm{X}$ & & $\mathrm{X}$ & & $\mathrm{X}$ & & & \\
\hline Ding (2011) & agri-food & $\mathrm{X}$ & $\mathrm{X}$ & & & & $\mathrm{X}$ & & & & & \\
\hline Ding (2013) & agri-food & $\mathrm{X}$ & $\mathrm{X}$ & & $\mathrm{X}$ & & $\mathrm{X}$ & & & & & \\
\hline Etemadnia et al. (2013) & agri-food & & $\mathrm{X}$ & $\mathrm{X}$ & $\mathrm{X}$ & & $\mathrm{X}$ & & & & & \\
\hline Etemadnia et al. (2015) & agri-food & & $\mathrm{X}$ & $\mathrm{X}$ & $\mathrm{X}$ & & $\mathrm{X}$ & & & & & \\
\hline Govindan et al. (2014) & agri-food & & $\mathrm{X}$ & $\mathrm{X}$ & $\mathrm{X}$ & & $\mathrm{X}$ & & $\mathrm{X}$ & & & \\
\hline Jonkman et al. (2017) & sugar & $\mathrm{X}$ & $\mathrm{X}$ & & $\mathrm{X}$ & & & $\mathrm{X}$ & & & & \\
\hline Jouzdani, Sadjadi, and Fathian (2013) & dairy & $\mathrm{X}$ & $\mathrm{X}$ & & & & & $\mathrm{X}$ & & & & \\
\hline Mohammed and Wang (2017a) & agri-food & $\mathrm{X}$ & $\mathrm{X}$ & & $\mathrm{X}$ & & $\mathrm{X}$ & & & & & \\
\hline Mohammed and Wang (2017b) & agri-food & $\mathrm{X}$ & $\mathrm{X}$ & & $\mathrm{X}$ & & $\mathrm{X}$ & & & $\mathrm{X}$ & & \\
\hline Mohammed and Wang (2017c) & agri-food & $\mathrm{X}$ & $\mathrm{X}$ & & $\mathrm{X}$ & & $\mathrm{X}$ & & & & & \\
\hline Neungmatcha et al. (2013) & sugar & $\mathrm{X}$ & $X$ & & & & $X$ & & & & & \\
\hline Reza-Nasiri and Davoudpour (2012) & agri-food & & & $\mathrm{X}$ & $\mathrm{X}$ & & & $\mathrm{X}$ & & & & \\
\hline Singh et al. (2016) & agri-food & & & $\mathrm{X}$ & $\mathrm{X}$ & & & $\mathrm{X}$ & $\mathrm{X}$ & & & \\
\hline Villa-Marulanda, Leguizamón, and Niño-Mora (2010) & agri-food & & $\mathrm{X}$ & $\mathrm{X}$ & & & $\mathrm{X}$ & & & & & \\
\hline Wouda et al. (2002) & dairy & $\mathrm{X}$ & $\mathrm{X}$ & $\mathrm{X}$ & & & & $\mathrm{X}$ & & & & \\
\hline Xiaohui and Wen (2009) & agri-food & & & $\mathrm{X}$ & $\mathrm{X}$ & & $\mathrm{X}$ & & $\mathrm{X}$ & & & \\
\hline Zhao and Dou (2011) & agri-food & $\mathrm{X}$ & $\mathrm{X}$ & $\mathrm{X}$ & & & & $X$ & $\mathrm{X}$ & & & \\
\hline Zhao and Lv (2011) & agri-food & $\mathrm{X}$ & $\mathrm{X}$ & $X$ & & & & $X$ & $\mathrm{X}$ & & & \\
\hline Zhi-lin and Dong (2007) & agri-food & & & $X$ & $\mathrm{X}$ & & $\mathrm{X}$ & & $\mathrm{X}$ & & & \\
\hline Total & & 14 & 24 & 16 & 22 & 0 & 18 & 12 & 8 & 2 & 0 & 1 \\
\hline$\%$ & & 46.7 & 80.0 & 53.3 & 73.3 & 0.0 & 60.0 & 40.0 & 26.7 & 6.7 & 0.0 & 3.3 \\
\hline
\end{tabular}


Table 4. Classification of decision characteristics

\begin{tabular}{|c|c|c|c|c|c|c|c|c|c|c|c|c|c|c|c|c|c|c|}
\hline \multirow[b]{2}{*}{ Reference } & \multicolumn{3}{|c|}{ Design decisions } & \multicolumn{12}{|c|}{ Additional decisions } & \multicolumn{3}{|c|}{ Time horizon } \\
\hline & FR & FL & $\mathrm{CA}$ & $\mathrm{MCF}$ & SA & FA & MA & ET & Inv & $\mathrm{Lab}$ & Proc & Prod & Rou & TQ & TM & $\mathrm{TC}$ & STP & MTP \\
\hline Accorsi et al. (2016) & $\mathrm{X}$ & $\mathrm{X}$ & $\mathrm{X}$ & & $\mathrm{X}$ & $\mathrm{X}$ & $\mathrm{X}$ & & & & & & & $\mathrm{X}$ & & & $\mathrm{X}$ & \\
\hline Allaoui et al. (2016) & $\mathrm{X}$ & $\mathrm{X}$ & $X$ & $X$ & $\mathrm{X}$ & $\mathrm{X}$ & $X$ & $\mathrm{X}$ & & & $X$ & $\mathrm{X}$ & & $\mathrm{X}$ & $\mathrm{X}$ & & & $\mathrm{X}$ \\
\hline Amorim et al. (2016) & & & & & $\mathrm{X}$ & $\mathrm{X}$ & $\mathrm{X}$ & & $\mathrm{X}$ & & $\mathrm{X}$ & $\mathrm{X}$ & & $\mathrm{X}$ & & & & $\mathrm{X}$ \\
\hline Apaiah and Hendrix (2005) & & $\mathrm{X}$ & & & & $\mathrm{X}$ & & & & & & $X$ & & $\mathrm{X}$ & $\mathrm{X}$ & & $\mathrm{X}$ & \\
\hline Baghalian, Rezapour, and Farahani (2013) & & $\mathrm{X}$ & & & & $\mathrm{X}$ & $\mathrm{X}$ & & & & & & $\mathrm{X}$ & $\mathrm{X}$ & & & $\mathrm{X}$ & \\
\hline Boudahri et al. (2011) & & $\mathrm{X}$ & & & & & $\mathrm{X}$ & & & & & & & & & & $\mathrm{X}$ & \\
\hline Boudahri et al. (2012a) & & $\mathrm{X}$ & & & & & $\mathrm{X}$ & & & & & & & & & & $\mathrm{X}$ & \\
\hline Boudahri et al. (2012b) & & $\mathrm{X}$ & & & & & $\mathrm{X}$ & & & & & & & & & & $\mathrm{X}$ & \\
\hline Boudahri et al. (2013) & & $\mathrm{X}$ & & & & & $\mathrm{X}$ & & & & & & $\mathrm{X}$ & & & & $\mathrm{X}$ & \\
\hline Colicchia et al. (2016) & & $\mathrm{X}$ & & & & & $\mathrm{X}$ & & & & & & & & & & $\mathrm{X}$ & \\
\hline Di et al. (2011) & & $\mathrm{X}$ & & & & & $\mathrm{X}$ & & & & & & & & & & $\mathrm{X}$ & \\
\hline Ding (2011) & & $\mathrm{X}$ & & & $\mathrm{X}$ & $\mathrm{X}$ & & & & & & & & $\mathrm{X}$ & & & $\mathrm{X}$ & \\
\hline Ding (2013) & & $X$ & & & $X$ & & $\mathrm{X}$ & & & & & & & $\mathrm{X}$ & & & $\mathrm{X}$ & \\
\hline Etemadnia et al. (2013) & & $\mathrm{X}$ & & & & $\mathrm{X}$ & $\mathrm{X}$ & & & & & & & $\mathrm{X}$ & & & $\mathrm{X}$ & \\
\hline Etemadnia et al. (2015) & & $\mathrm{X}$ & & & & $\mathrm{X}$ & $\mathrm{X}$ & & & & & & & $\mathrm{X}$ & $\mathrm{X}$ & & $\mathrm{X}$ & \\
\hline Govindan et al. (2014) & & $\mathrm{X}$ & & & & $\mathrm{X}$ & $\mathrm{X}$ & & $\mathrm{X}$ & & & $\mathrm{X}$ & $\mathrm{X}$ & $\mathrm{X}$ & & $\mathrm{X}$ & & $\mathrm{X}$ \\
\hline Jonkman et al. (2017) & $\mathrm{X}$ & $\mathrm{X}$ & $\mathrm{X}$ & & $\mathrm{X}$ & $\mathrm{X}$ & $\mathrm{X}$ & & & & & & & $\mathrm{X}$ & & & & $\mathrm{X}$ \\
\hline Jouzdani, Sadjadi, and Fathian (2013) & $\mathrm{X}$ & $\mathrm{X}$ & & & & $\mathrm{X}$ & & & & & & & & $\mathrm{X}$ & & & & $\mathrm{X}$ \\
\hline Mohammed and Wang (2017a) & & $\mathrm{X}$ & & & $\mathrm{X}$ & & $\mathrm{X}$ & & & & & & & $\mathrm{X}$ & & & $\mathrm{X}$ & \\
\hline Mohammed and Wang (2017b) & & $\mathrm{X}$ & & & $\mathrm{X}$ & & $\mathrm{X}$ & & & $\mathrm{X}$ & & & & $\mathrm{X}$ & & & $\mathrm{X}$ & \\
\hline Mohammed and Wang (2017c) & & $\mathrm{X}$ & & & $\mathrm{X}$ & & $\mathrm{X}$ & & & $\mathrm{X}$ & & & & $\mathrm{X}$ & & & $\mathrm{X}$ & \\
\hline Neungmatcha et al. (2013) & & $\mathrm{X}$ & $\mathrm{X}$ & & $\mathrm{X}$ & & & & & & & & & & & & $\mathrm{X}$ & \\
\hline Reza-Nasiri and Davoudpour (2012) & & $\mathrm{X}$ & $\mathrm{X}$ & & & & $\mathrm{X}$ & & & & & & & & & & $\mathrm{X}$ & \\
\hline Singh et al. (2016) & & $\mathrm{X}$ & & $\mathrm{X}$ & & & $\mathrm{X}$ & & & & & & & $\mathrm{X}$ & & & $\mathrm{X}$ & \\
\hline Villa-Marulanda, Leguizamón, and Niño-Mora (2010) & & $\mathrm{X}$ & & & & & $\mathrm{X}$ & & & & & & & & & & $\mathrm{X}$ & \\
\hline Wouda et al. (2002) & $\mathrm{X}$ & $\mathrm{X}$ & & & $\mathrm{X}$ & $\mathrm{X}$ & $\mathrm{X}$ & & & & $\mathrm{X}$ & $\mathrm{X}$ & & $\mathrm{X}$ & & & $\mathrm{X}$ & \\
\hline Xiaohui and Wen (2009) & & $\mathrm{X}$ & & & & & $\mathrm{X}$ & & & & & & & & & & $\mathrm{X}$ & \\
\hline Zhao and Dou (2011) & $\mathrm{X}$ & $\mathrm{X}$ & & & $\mathrm{X}$ & $\mathrm{X}$ & $\mathrm{X}$ & & & & $\mathrm{X}$ & $\mathrm{X}$ & & $\mathrm{X}$ & $\mathrm{X}$ & & $\mathrm{X}$ & \\
\hline Zhao and Lv (2011) & $\mathrm{X}$ & $\mathrm{X}$ & & & $\mathrm{X}$ & $\mathrm{X}$ & $\mathrm{X}$ & & & & $\mathrm{X}$ & $\mathrm{X}$ & & $\mathrm{X}$ & $\mathrm{X}$ & & $\mathrm{X}$ & \\
\hline Zhi-lin and Dong (2007) & & $X$ & & & & & $\mathrm{X}$ & & & & & & & & & & $\mathrm{X}$ & \\
\hline Total & 6 & 29 & 5 & 2 & 13 & 14 & 26 & 1 & 2 & 2 & 5 & 7 & 3 & 19 & 5 & 1 & 25 & 5 \\
\hline$\%$ & 20.0 & 96.7 & 16.7 & 6.7 & 43.3 & 46.7 & 86.7 & 3.3 & 6.7 & 6.7 & 16.7 & 23.3 & 10.0 & 63.3 & 16.7 & 3.3 & 83.3 & 16.7 \\
\hline
\end{tabular}

FR: Facility role, FL: Facility location, CA: Capacity allocation, MCF: Maintain/Close facility, SA: Supply allocation, FA: Facility allocation, MA: Market allocation; ET: Energy type, Inv: Inventory, Lab: Labouring, Proc: Procurement, Prod: Production, Rou: Routing, TQ: Transported quantity, TM: Transport mode, TC: Transport capacity; STP: Single time period, MTP: Multiple time period 
Table 5. Classification of the modelling approach (Part I)

\begin{tabular}{|c|c|c|c|c|c|c|c|c|c|c|c|}
\hline \multirow[b]{2}{*}{ Reference } & \multicolumn{7}{|c|}{ Model type } & \multicolumn{4}{|l|}{ Model purpose } \\
\hline & LP & MILP & MOILP & INLP & SP & FMP & ALG/HEU & Max. profit & Min. cost & $\begin{array}{c}\text { Min. negative } \\
\text { environmental impact }\end{array}$ & $\begin{array}{l}\text { Max. positive } \\
\text { social impact }\end{array}$ \\
\hline Accorsi et al. (2016) & $\mathrm{X}$ & & & & & & & & $\mathrm{X}$ & & \\
\hline Allaoui et al. (2016) & & & $\mathrm{X}$ & & & & $\mathrm{X}$ & & $\mathrm{X}$ & $\mathrm{X}$ & $\mathrm{X}$ \\
\hline Amorim et al. (2016) & & & & & $\mathrm{X}$ & & $\mathrm{X}$ & $\mathrm{X}$ & & & $\mathrm{X}$ \\
\hline Apaiah and Hendrix (2005) & $\mathrm{X}$ & & & & & & & & $\mathrm{X}$ & & \\
\hline Baghalian, Rezapour, and Farahani (2013) & & & & $\mathrm{X}$ & & & & $X$ & & & \\
\hline Boudahri et al. (2011) & & $\mathrm{X}$ & & & & & & & $\mathrm{X}$ & & \\
\hline Boudahri et al. (2012a) & & $\mathrm{X}$ & & & & & & & $\mathrm{X}$ & & \\
\hline Boudahri et al. (2012b) & & $\mathrm{X}$ & & & & & & & $\mathrm{X}$ & & \\
\hline Boudahri et al. (2013) & & $\mathrm{X}$ & & & & & & & $\mathrm{X}$ & & \\
\hline Colicchia et al. (2016) & & & $\mathrm{X}$ & & & & & & $\mathrm{X}$ & $\mathrm{X}$ & \\
\hline Di et al. (2011) & & $\mathrm{X}$ & & & & & $\mathrm{X}$ & & $X$ & & \\
\hline Ding (2011) & & & & & $\mathrm{X}$ & & $X$ & & $\mathrm{X}$ & & \\
\hline Ding (2013) & & & & & $X$ & & $X$ & & $X$ & & \\
\hline Etemadnia et al. (2013) & & $\mathrm{X}$ & & & & & & & $\mathrm{X}$ & & \\
\hline Etemadnia et al. (2015) & & $\mathrm{X}$ & & & & & $\mathrm{X}$ & & $\mathrm{X}$ & & \\
\hline Govindan et al. (2014) & & & $\mathrm{X}$ & & & & $\mathrm{X}$ & & $\mathrm{X}$ & $X$ & \\
\hline Jonkman et al. (2017) & & $\mathrm{X}$ & & & & & & $\mathrm{X}$ & & & \\
\hline Jouzdani, Sadjadi, and Fathian (2013) & & & & & & $\mathrm{X}$ & & & $\mathrm{X}$ & & \\
\hline Mohammed and Wang (2017a) & & & & & & $\mathrm{X}$ & & & $\mathrm{X}$ & & $\mathrm{X}$ \\
\hline Mohammed and Wang (2017b) & & & $\mathrm{X}$ & & & & $\mathrm{X}$ & & $\mathrm{X}$ & & $\mathrm{X}$ \\
\hline Mohammed and Wang (2017c) & & & & & & $\mathrm{X}$ & $\mathrm{X}$ & & $\mathrm{X}$ & $X$ & $\mathrm{X}$ \\
\hline Neungmatcha et al. (2013) & & $\mathrm{X}$ & & & & & $\mathrm{X}$ & & $\mathrm{X}$ & & \\
\hline Reza-Nasiri and Davoudpour (2012) & & & & & $\mathrm{X}$ & & & & $\mathrm{X}$ & & $\mathrm{X}$ \\
\hline Singh et al. (2016) & & $\mathrm{X}$ & & & & & & & $\mathrm{X}$ & & \\
\hline Villa-Marulanda, Leguizamón, and Niño-Mora (2010) & & $\mathrm{X}$ & & & & & $\mathrm{X}$ & & $\mathrm{X}$ & & \\
\hline Wouda et al. (2002) & & $\mathrm{X}$ & & & & & & & $\mathrm{X}$ & & \\
\hline Xiaohui and Wen (2009) & & $\mathrm{X}$ & & & & & & & $\mathrm{X}$ & & \\
\hline Zhao and Dou (2011) & & $\mathrm{X}$ & & & & & $\mathrm{X}$ & & $\mathrm{X}$ & & \\
\hline Zhao and Lv (2011) & & $X$ & & & & & $X$ & & $X$ & & \\
\hline Zhi-lin and Dong (2007) & & $\mathrm{X}$ & & & & & & & $X$ & & \\
\hline Total & 2 & 16 & 4 & 1 & 4 & 3 & 13 & 3 & 27 & 4 & 6 \\
\hline$\%$ & 6.7 & 53.3 & 13.3 & 3.3 & 13.3 & 10.0 & 43.3 & 10.0 & 90.0 & 13.3 & 20.0 \\
\hline
\end{tabular}


Table 6. Classification of the modelling approach (Part II)

\begin{tabular}{|c|c|c|c|c|c|c|c|c|c|c|c|c|c|}
\hline \multirow{2}{*}{ Reference } & \multicolumn{11}{|c|}{ Model constraints } & \multicolumn{2}{|c|}{$\begin{array}{l}\text { Model } \\
\text { application }\end{array}$} \\
\hline & Supply & Capacity & $\begin{array}{c}\text { No. of } \\
\text { locations }\end{array}$ & Distance & Budget & Waste & Time & $\begin{array}{c}\text { Service } \\
\text { level }\end{array}$ & Production & Routes & Perishability & $\begin{array}{l}\text { Real } \\
\text { case }\end{array}$ & $\begin{array}{l}\text { Case } \\
\text { study }\end{array}$ \\
\hline Accorsi et al. (2016) & & $X$ & & & & & & & & & & & $\mathrm{X}$ \\
\hline Allaoui et al. (2016) & $\mathrm{X}$ & $\mathrm{X}$ & & & & & & & & & & & $\mathrm{X}$ \\
\hline Amorim et al. (2016) & $X$ & $X$ & & & & & & & & & & & $X$ \\
\hline Apaiah and Hendrix (2005) & & & & & & & & & & & & & $\mathrm{X}$ \\
\hline Baghalian, Rezapour, and Farahani (2013) & & $X$ & & & $X$ & & & & & $X$ & & $X$ & \\
\hline Boudahri et al. (2011) & & $\mathrm{X}$ & & & & & & & & & & & $\mathrm{X}$ \\
\hline Boudahri et al. (2012a) & & $X$ & & & & & & & & & & & $\mathrm{X}$ \\
\hline Boudahri et al. (2012b) & & $\mathrm{X}$ & & & & & & & & & & & $\mathrm{X}$ \\
\hline Boudahri et al. (2013) & & $X$ & & & & & & & & & & $\mathrm{X}$ & \\
\hline Colicchia et al. (2016) & & $\mathrm{X}$ & & $\mathrm{X}$ & & & & & & & & & $\mathrm{X}$ \\
\hline Di et al. (2011) & & & $\mathrm{X}$ & & & & & & & & & & $\mathrm{X}$ \\
\hline Ding (2011) & & $\mathrm{X}$ & $\mathrm{X}$ & $\mathrm{X}$ & & & & & & & & & $\mathrm{X}$ \\
\hline Ding (2013) & & & & $\mathrm{X}$ & & & & $\mathrm{X}$ & & & & & $\mathrm{X}$ \\
\hline Etemadnia et al. (2013) & $\mathrm{X}$ & $\mathrm{X}$ & & $\mathrm{X}$ & & & & & & & & $\mathrm{X}$ & \\
\hline Etemadnia et al. (2015) & $\mathrm{X}$ & $\mathrm{X}$ & & $\mathrm{X}$ & & & & & & & & & $\mathrm{X}$ \\
\hline Govindan et al. (2014) & & $\mathrm{X}$ & $X$ & & & & $\mathrm{X}$ & & & & & & $\mathrm{X}$ \\
\hline Jonkman et al. (2017) & $\mathrm{X}$ & $\mathrm{X}$ & & & & & & & & & & & $\mathrm{X}$ \\
\hline Jouzdani, Sadjadi, and Fathian (2013) & & $\mathrm{X}$ & & & & & & & & $\mathrm{X}$ & & & $\mathrm{X}$ \\
\hline Mohammed and Wang (2017a) & $X$ & $X$ & & & & & & & & & & & $\mathrm{X}$ \\
\hline Mohammed and Wang (2017b) & $\mathrm{X}$ & $\mathrm{X}$ & & & & & $\mathrm{X}$ & & & & & & $\mathrm{X}$ \\
\hline Mohammed and Wang (2017c) & $\mathrm{X}$ & $\mathrm{X}$ & & & & & $\mathrm{X}$ & & & & & & $\mathrm{X}$ \\
\hline Neungmatcha et al. (2013) & $\mathrm{X}$ & $X$ & & & & & & & & & & & $X$ \\
\hline Reza-Nasiri and Davoudpour (2012) & & $X$ & & & & & & & & & & & $X$ \\
\hline Singh et al. (2016) & & $\mathrm{X}$ & & $\mathrm{X}$ & & & & & & & & & $\mathrm{X}$ \\
\hline Villa-Marulanda, Leguizamón, and Niño-Mora (2010) & & $\mathrm{X}$ & & & & & & & & & & & $\mathrm{X}$ \\
\hline Wouda et al. (2002) & $\mathrm{X}$ & & $\mathrm{X}$ & & & & & & & & & $\mathrm{X}$ & \\
\hline Xiaohui and Wen (2009) & & & $\mathrm{X}$ & & & & & & & & & & $\mathrm{X}$ \\
\hline Zhao and Dou (2011) & $\mathrm{X}$ & & & & & & $\mathrm{X}$ & & $\mathrm{X}$ & & & & $\mathrm{X}$ \\
\hline Zhao and Lv (2011) & $\mathrm{X}$ & & & & & & $\mathrm{X}$ & & $\mathrm{X}$ & & & & $\mathrm{X}$ \\
\hline Zhi-lin and Dong (2007) & & $\mathrm{X}$ & & & & $\mathrm{X}$ & & & & & & & $\mathrm{X}$ \\
\hline Total & 12 & 23 & 5 & 6 & 1 & 1 & 5 & 1 & 2 & 2 & 0 & 4 & 26 \\
\hline$\%$ & 40.0 & 76.7 & 16.7 & 20.0 & 3.3 & 3.3 & 16.7 & 3.3 & 6.7 & 6.7 & 0.0 & 13.3 & 86.7 \\
\hline
\end{tabular}


Table 7. Costs accounted in economic objectives

\begin{tabular}{|c|c|c|c|c|c|c|c|c|c|c|c|}
\hline \multirow[b]{2}{*}{ Reference } & \multicolumn{11}{|l|}{ Costs } \\
\hline & $\begin{array}{l}\text { Locating } \\
\text { facility }\end{array}$ & Production & Transport & Inventory & $\begin{array}{l}\text { Product } \\
\text { loss }\end{array}$ & Procurement & $\begin{array}{c}\text { Unmet } \\
\text { demand }\end{array}$ & Energy & $\begin{array}{l}\text { Closing } \\
\text { location }\end{array}$ & RFID & Labouring \\
\hline Accorsi et al. (2016) & $\mathrm{X}$ & & $\mathrm{X}$ & & & & & & & & \\
\hline Allaoui et al. (2016) & $\mathrm{X}$ & $\mathrm{X}$ & $X$ & & & $\mathrm{X}$ & & & $\mathrm{X}$ & & \\
\hline Apaiah and Hendrix (2005) & & $\mathrm{X}$ & $\mathrm{X}$ & & & $\mathrm{X}$ & & & & & \\
\hline Baghalian, Rezapour, and Farahani (2013) & $X$ & $\mathrm{X}$ & $\mathrm{X}$ & $X$ & & & $\mathrm{X}$ & & & & \\
\hline Boudahri et al. (2011) & $\mathrm{X}$ & & $\mathrm{X}$ & & & & & & & & \\
\hline Boudahri et al. (2012a) & $\mathrm{X}$ & & $\mathrm{X}$ & & & & & & & & \\
\hline Boudahri et al. (2013) & $\mathrm{X}$ & & $\mathrm{X}$ & & & & & & & & \\
\hline Colicchia et al. (2016) & & & $X$ & & & & & & & & \\
\hline Di et al. (2011) & $\mathrm{X}$ & $\mathrm{X}$ & $\mathrm{X}$ & $\mathrm{X}$ & $\mathrm{X}$ & & & & & & \\
\hline Ding (2011) & $\mathrm{X}$ & $\mathrm{X}$ & $\mathrm{X}$ & & $\mathrm{X}$ & & & & & & \\
\hline Ding (2013) & $\mathrm{X}$ & $X$ & $\mathrm{X}$ & & & & & & & & \\
\hline Etemadnia et al. (2013) & $\mathrm{X}$ & & $X$ & & & & & & & & \\
\hline Etemadnia et al. (2015) & $\mathrm{X}$ & & $\mathrm{X}$ & & & & & & & & \\
\hline Govindan et al. (2014) & $\mathrm{X}$ & $\mathrm{X}$ & $\mathrm{X}$ & $\mathrm{X}$ & & & $\mathrm{X}$ & & & & \\
\hline Jonkman et al. (2017) & $\mathrm{X}$ & $\mathrm{X}$ & $\mathrm{X}$ & & & & & & & & \\
\hline Jouzdani, Sadjadi, and Fathian (2013) & $\mathrm{X}$ & & $\mathrm{X}$ & & & & & & & & \\
\hline Mohammed and Wang (2017b) & & & $\mathrm{X}$ & & & & & & & $\mathrm{X}$ & $\mathrm{X}$ \\
\hline Mohammed and Wang (2017c) & & $\mathrm{X}$ & $\mathrm{X}$ & & & & & & & $\mathrm{X}$ & \\
\hline Neungmatcha et al. (2013) & $\mathrm{X}$ & $\mathrm{X}$ & $\mathrm{X}$ & & & & & & & & \\
\hline Reza-Nasiri and Davoudpour (2012) & $\mathrm{X}$ & & $\mathrm{X}$ & $\mathrm{X}$ & & $\mathrm{X}$ & & & & & \\
\hline Singh et al. (2016) & $\mathrm{X}$ & & $\mathrm{X}$ & & & & $\mathrm{X}$ & $\mathrm{X}$ & $\mathrm{X}$ & & \\
\hline Villa-Marulanda, Leguizamón, and Niño-Mora (2010) & $\mathrm{X}$ & & $\mathrm{X}$ & & & & & & & & \\
\hline Wouda et al. (2002) & & $\mathrm{X}$ & $\mathrm{X}$ & & & $\mathrm{X}$ & & & & & \\
\hline Xiaohui and Wen (2009) & $\mathrm{X}$ & & $\mathrm{X}$ & & $\mathrm{X}$ & & & & & & \\
\hline Zhao and Dou (2011) & & $\mathrm{X}$ & $\mathrm{X}$ & $\mathrm{X}$ & & & & & & & \\
\hline Zhao and Lv (2011) & & $X$ & $X$ & $X$ & & & & & & & \\
\hline Zhi-lin and Dong (2007) & & & $\mathrm{X}$ & & $\mathrm{X}$ & & & & & & \\
\hline Total & 20 & 14 & 30 & 7 & 4 & 5 & 3 & 1 & 2 & 3 & 1 \\
\hline$\%$ & 66.7 & 46.7 & 100.0 & 23.3 & 13.3 & 16.7 & 10.0 & 3.3 & 6.7 & 10.0 & 3.3 \\
\hline
\end{tabular}


Table 8. Classification of uncertainty modelling

\begin{tabular}{|c|c|c|c|c|c|c|c|c|c|c|c|c|c|c|c|c|c|c|c|}
\hline \multirow{3}{*}{ Reference } & \multirow{2}{*}{\multicolumn{2}{|c|}{$\begin{array}{l}\text { Modelling } \\
\text { context }\end{array}$}} & \multicolumn{15}{|c|}{ Uncertain parameters } & \multirow{2}{*}{\multicolumn{2}{|c|}{ Uncertainty type }} \\
\hline & & & \multicolumn{5}{|c|}{ Product } & \multicolumn{5}{|c|}{ Process } & \multicolumn{2}{|c|}{ Market } & \multicolumn{3}{|c|}{ Environment } & & \\
\hline & Det & Unc & SL & DR & $\mathrm{H}$ & FQ & FS & $\mathrm{S}$ & LT & RN & Prod & $\mathrm{C}$ & $\mathrm{D}$ & MP & W & PD & $\mathrm{R}$ & Ep & $\mathrm{Al}$ \\
\hline Accorsi et al. (2016) & $\mathrm{X}$ & & & & & & & & & & & & & & & & & & \\
\hline Allaoui et al. (2016) & $\mathrm{X}$ & & & & & & & & & & & & & & & & & & \\
\hline Amorim et al. (2016) & & $\mathrm{X}$ & & & & & & $\mathrm{X}$ & $\mathrm{X}$ & & & $\mathrm{X}$ & $\mathrm{X}$ & & & & & & $\mathrm{X}$ \\
\hline Apaiah and Hendrix (2005) & $\mathrm{X}$ & & & & & & & & & & & & & & & & & & \\
\hline Baghalian, Rezapour, and Farahani (2013) & & $\mathrm{X}$ & & & & & & $\mathrm{X}$ & & & & & $\mathrm{X}$ & & & & & & $\mathrm{X}$ \\
\hline Boudahri et al. (2011) & $\mathrm{X}$ & & & & & & & & & & & & & & & & & & \\
\hline Boudahri et al. (2012a) & $\mathrm{X}$ & & & & & & & & & & & & & & & & & & \\
\hline Boudahri et al. (2012b) & $\mathrm{X}$ & & & & & & & & & & & & & & & & & & \\
\hline Boudahri et al. (2013) & $\mathrm{X}$ & & & & & & & & & & & & & & & & & & \\
\hline Colicchia et al. (2016) & $\mathrm{X}$ & & & & & & & & & & & & & & & & & & \\
\hline Di et al. (2011) & $\mathrm{X}$ & & & & & & & & & & & & & & & & & & \\
\hline Ding (2011) & & $\mathrm{X}$ & & & & & & & & & & $X$ & & & & & & & $\mathrm{X}$ \\
\hline Ding (2013) & & $\mathrm{X}$ & & & & & & $\mathrm{X}$ & & & & $\mathrm{X}$ & & & & & & & $\mathrm{X}$ \\
\hline Etemadnia et al. (2013) & $\mathrm{X}$ & & & & & & & & & & & & & & & & & & \\
\hline Etemadnia et al. (2015) & $\mathrm{X}$ & & & & & & & & & & & & & & & & & & \\
\hline Govindan et al. (2014) & $\mathrm{X}$ & & & & & & & & & & & & & & & & & & \\
\hline Jonkman et al. (2017) & $\mathrm{X}$ & & & & & & & & & & & & & & & & & & \\
\hline Jouzdani, Sadjadi, and Fathian (2013) & & $\mathrm{X}$ & & & & & & & & & & & $\mathrm{X}$ & & & & & $\mathrm{X}$ & \\
\hline Mohammed and Wang (2017a) & & $\mathrm{X}$ & & & & & & & & & & & $\mathrm{X}$ & & & & & $\mathrm{X}$ & \\
\hline Mohammed and Wang (2017b) & $\mathrm{X}$ & & & & & & & & & & & & & & & & & & \\
\hline Mohammed and Wang (2017c) & & $\mathrm{X}$ & & & & & & $\mathrm{X}$ & & & & $X$ & $X$ & & & & & $X$ & \\
\hline Neungmatcha et al. (2013) & $\mathrm{X}$ & & & & & & & & & & & & & & & & & & \\
\hline Reza-Nasiri and Davoudpour (2012) & & $\mathrm{X}$ & & & & & & & & & & & $\mathrm{X}$ & & & & & & $\mathrm{X}$ \\
\hline Singh et al. (2016) & $\mathrm{X}$ & & & & & & & & & & & & & & & & & & \\
\hline Villa-Marulanda, Leguizamón, and Niño-Mora (2010) & $\mathrm{X}$ & & & & & & & & & & & & & & & & & & \\
\hline Wouda et al. (2002) & $\mathrm{X}$ & & & & & & & & & & & & & & & & & & \\
\hline Xiaohui and Wen (2009) & $\mathrm{X}$ & & & & & & & & & & & & & & & & & & \\
\hline Zhao and Dou (2011) & $\mathrm{X}$ & & & & & & & & & & & & & & & & & & \\
\hline Zhao and Lv (2011) & $\mathrm{X}$ & & & & & & & & & & & & & & & & & & \\
\hline Zhi-lin and Dong (2007) & $\mathrm{X}$ & & & & & & & & & & & & & & & & & & \\
\hline Total & 22 & 8 & 0 & 0 & 0 & 0 & 0 & 4 & 1 & 0 & 0 & 4 & 6 & 0 & 0 & 0 & 0 & 3 & 5 \\
\hline$\%$ & 73.3 & 26.7 & 0.0 & 0.0 & 0.0 & 0.0 & 0.0 & 13.3 & 3.3 & 0.0 & 0.0 & 13.3 & 20.0 & 0.0 & 0.0 & 0.0 & 0.0 & 10.0 & 16.7 \\
\hline
\end{tabular}

Det: Deterministic, Unc: Uncertain; SL: Shelf life, DR: Deterioration rate, H: Heterogeneity, FQ: Food quality, FS: Food safety; S: Supply, LT: Lead time, RN: Resource needs, Prod: Production, C: Costs; D: Demand, MP: Market prices; W: Weather, PD: Pests/diseases, R: Regulations; Ep: Epistemic, Al: Aleatory 


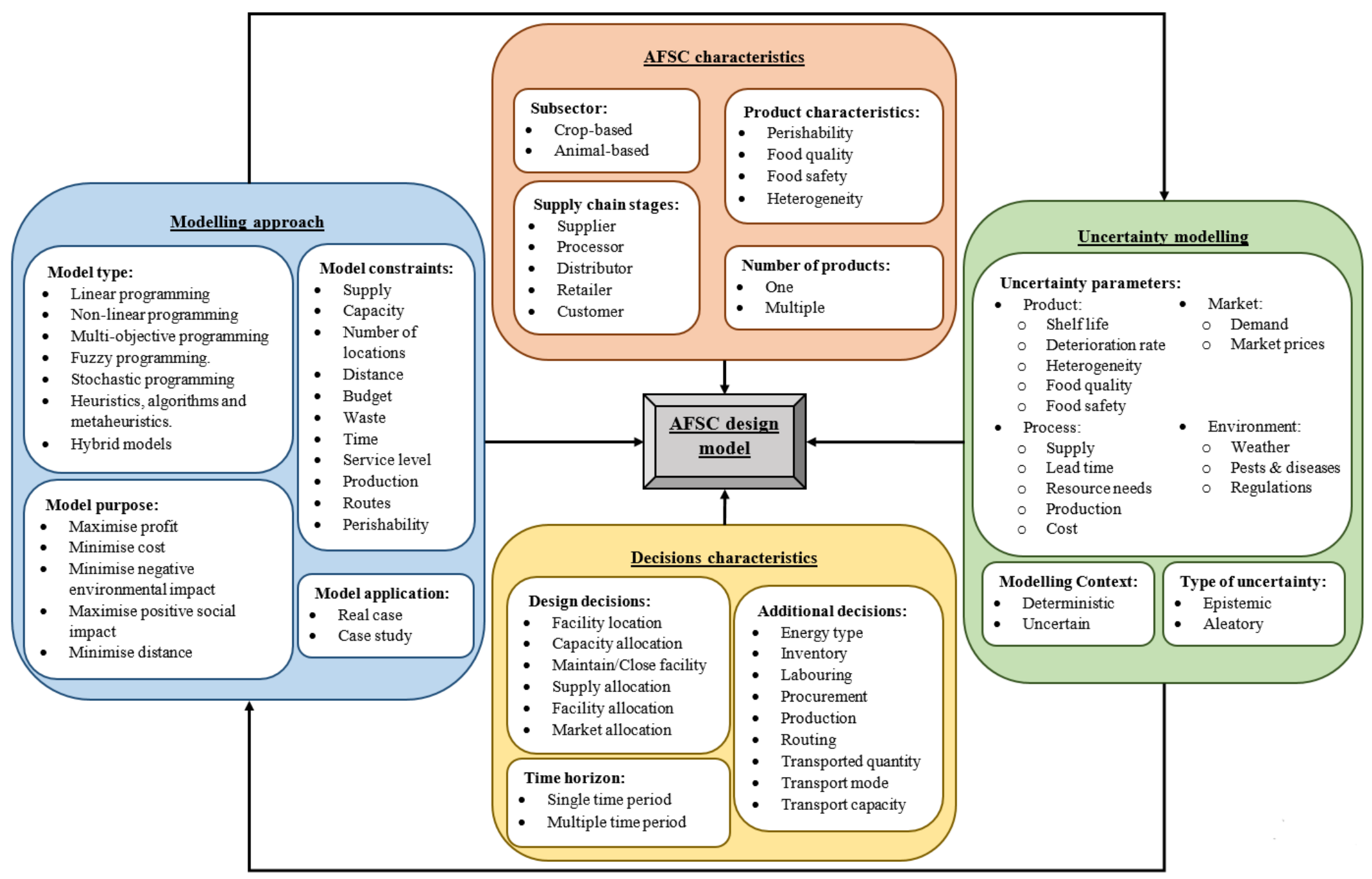

Figure 1: Conceptual framework for designing AFSC 


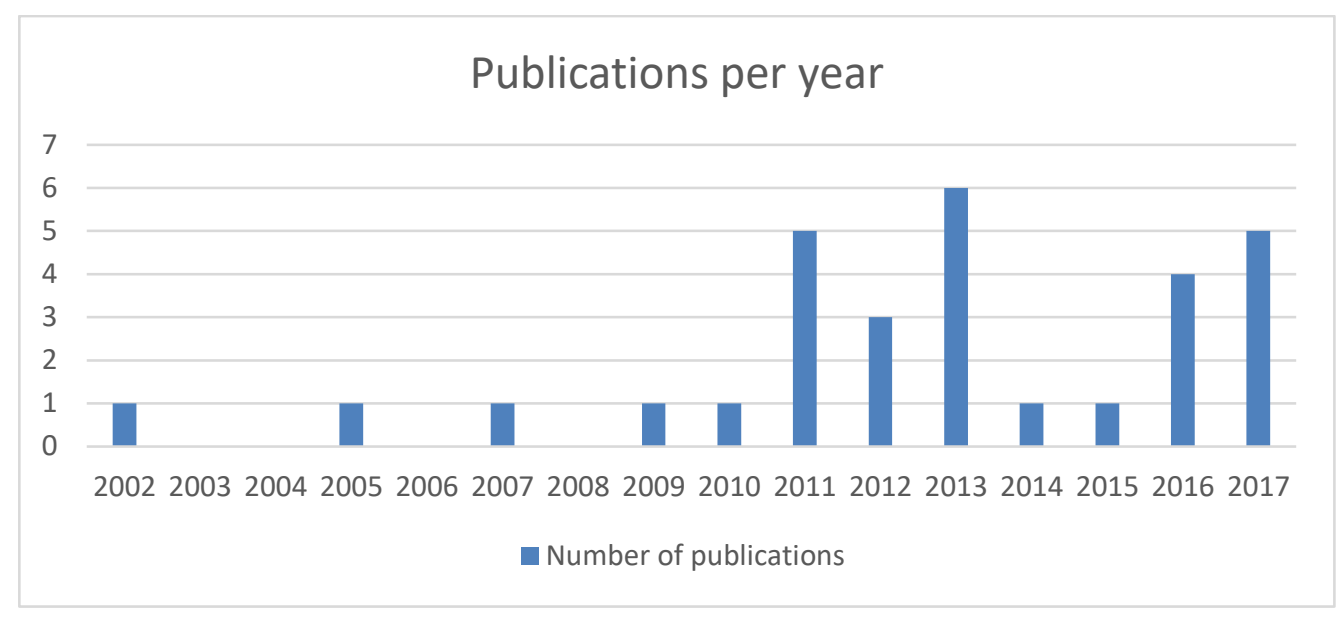

Figure 2: Number of publications per year 


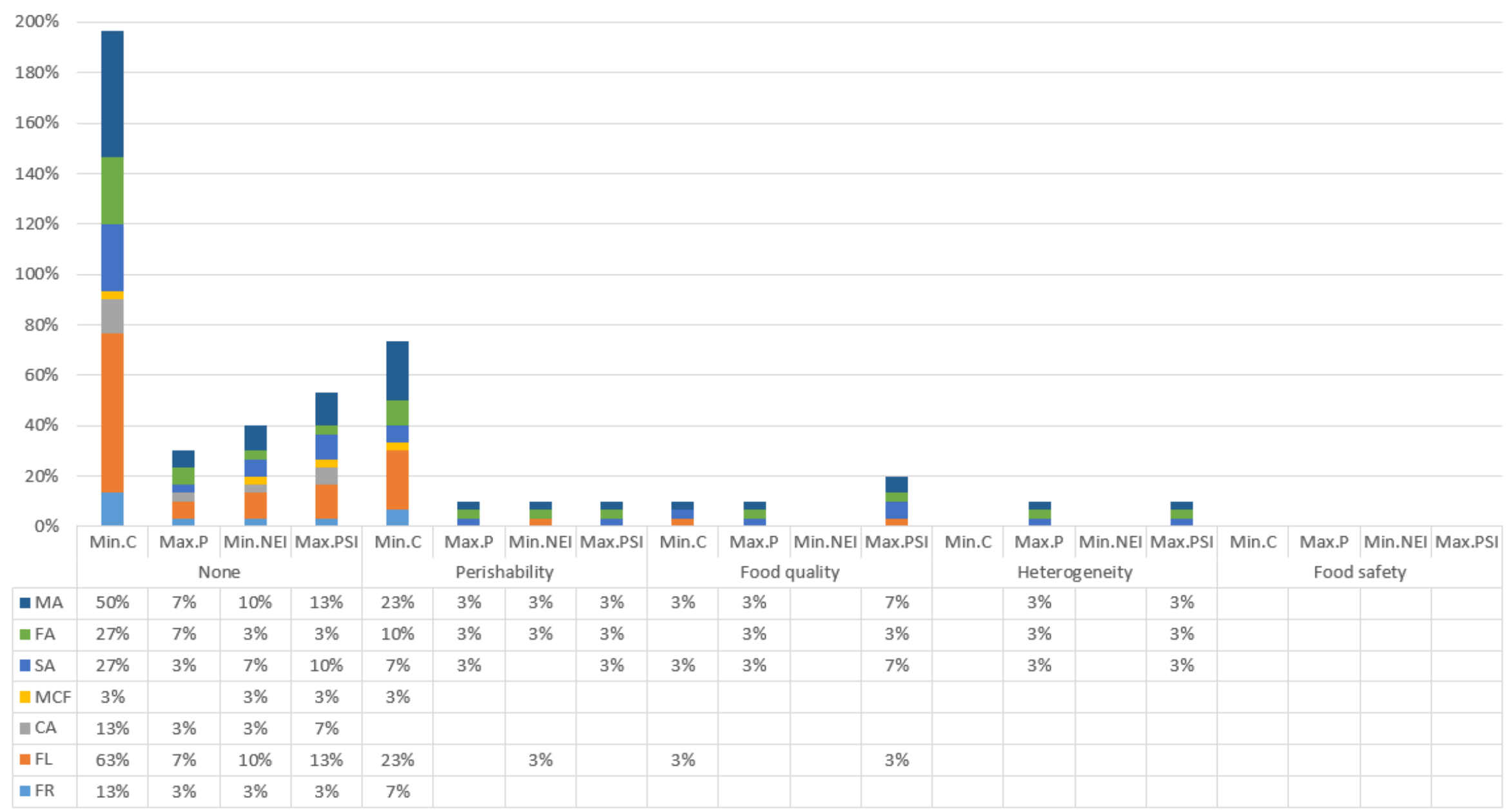

Figure 3: Design decisions versus Model purpose and Product characteristics 


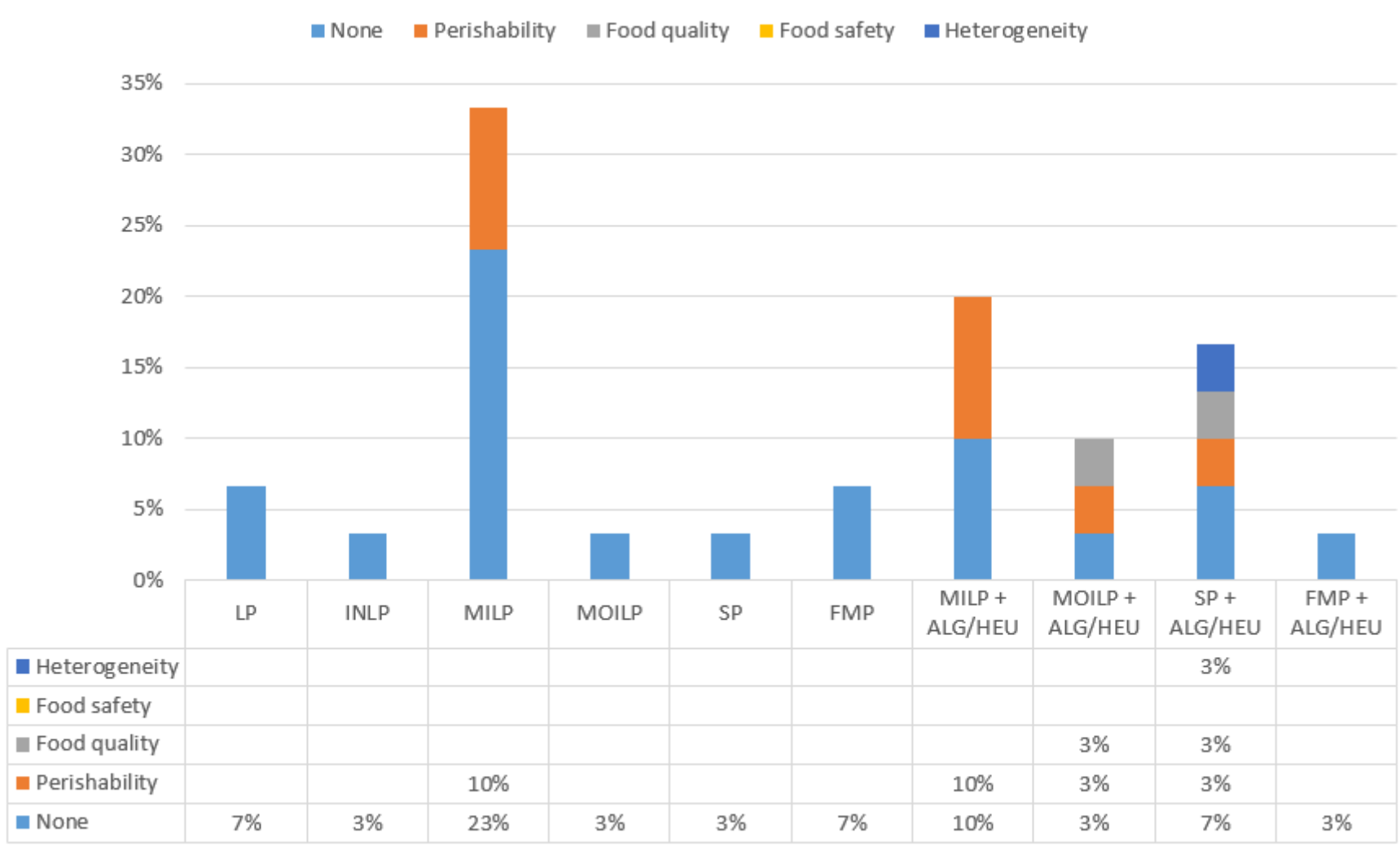

Figure 4: Model type versus Product characteristics 